\title{
Las descripciones de Hibernia en los colegios del exilio irlandés en Castilla: corografías literarias, colecciones de prodigios e imaginario político ${ }^{*}$
}

\author{
Javier Burguillo \\ Universidad de Salamanca \\ jburguillo@usal.es
}

Recepción: 24/03/2019, Aceptación: 29/04/2019, Publicación: 04/12/2019

\begin{abstract}
Resumen
El presente trabajo ofrece una visión de conjunto del exilio católico irlandés durante la temprana Edad Moderna a partir de la identificación y el análisis de una colección manuscrita de descripciones corográficas de Irlanda que se conservan en el Archivo Histórico de la Universidad de Salamanca. Fueron compuestas en los colegios del exilio y su estudio nos permite conocer mejor la vida intelectual de dichos colegios y entender las líneas de fuerza del discurso de exilio irlandés y su relación con los intereses literarios de la Castilla del momento.
\end{abstract}

Palabras clave

corografía; colegios del exilio; Hibernia; Irlanda

\begin{abstract}
The descriptions of Hibernia in the colleges of Irish exile in Castile: literary chorography, collections of marvels and political imaginary

This paper offers an overview of the Irish Catholic exile during the early Modern Era, based on the identification and analysis of a manuscript collection of chorographic descriptions of Ireland that are kept at the Historical Text Archive of the University of Salamanca. They were written in the colleges of the exile, and their study allows us a better grasp of the intellectual life of such colleges, as well as understanding the main ideas of the Irish exile discourse and its relationship with the literary interests of the Castile of that time period.
\end{abstract}

Keywords

chorography; colleges of the exile; Hibernia; Ireland

\footnotetext{
* Este trabajo se ha desarrollado en el marco del proyecto de investigación «Discursos y prácticas editoriales antianglicanas en Castilla»(FFI2014-61226-JIN), financiado por el Ministerio de Economía y Competitividad del Gobierno de España. Los libros consultados en la Biblioteca General Histórica de la Universidad de Salamanca se citarán como USAL BG.
} 
En la iglesia romana de san Gregorio Magno se conserva la lápida funeraria de sir Robert Peckham (1516-1569), un católico inglés que huyó de Londres y abandonó su carrera política para poder practicar la fe de sus padres en el exilio, y que murió en Roma a los pocos años porque no podía vivir lejos de su patria. ${ }^{1}$ Como es bien sabido, desde los albores del Estado moderno se asentó como verdad indiscutible el principio por el cual toda comunidad política se debía identificar con una religión determinada, con la religión de su rey (cuius regio eius religio), de forma que el monarca imponía a los súbditos un credo preciso que servía como elemento de cohesión para todo el territorio. El epitafio de sir Robert cifra de un modo elocuente el drama personal de todos aquellos que se vieron forzados a abandonar su lugar de nacimiento si querían ser fieles a sus creencias, y de modo particular el caso de los habitantes de las Islas Británicas, cuya situación fue más dramática, si cabe, que en otros lugares, porque los presupuestos del anglicanismo se impusieron sobre una población que estaba aún muy vinculada a la vieja religión, ${ }^{2}$ y porque su implantación se llevó a cabo a través de un proceso muy largo — desde Enrique VIII hasta Cromwell—, con periodos de gran represión del papismo que se alternaron con momentos de restauración o de mayor tolerancia del catolicismo: una inestabilidad que tuvo como reflejo la sucesión de tiempos de clandestinidad y tiempos de tensa convivencia hasta que la identidad anglicana del pueblo inglés se consolidó definitivamente.

Este trabajo forma parte de una investigación que pretende observar las nuevas formas de vida a que se vio abocada la población disidente en las Islas Británicas y analizar a través de qué discursos y prácticas culturales procuraron sostener su identidad religiosa, con un interés especial por las iniciativas literarias que se llevaron a cabo en y desde la Península Ibérica merced a la labor de los exiliados que buscaban el amparo de la Monarquía Hispánica. ${ }^{3}$

1. Actualmente, la lápida se lee con dificultad, pero el texto se conserva gracias a Gibelli (1888: 90): «Roberto Pechamo, anglo, equiti aurato, Philippo et Mariae, Angliae et Hispaniae regibus, olim a consiliis, genere, religione et virtute praeclaro, qui cum patriam suam a fide catholica deficientem adspicere, sine summo dolore non posset, relictis omnibus, quae in hac vita carissima esse solent, in voluntarium profectus exilium, post sex annos pauperibus Christi heredibus testamento institutis sanctissime e vita migravit». Para los avatares biográficos de Peckham, véase Dale (1982).

2. Y que lo siguió estando de forma clandestina y en porcentajes muy elevados durante décadas. Se puede citar aquí, como botón de muestra, la carta que el embajador de la Monarquía Hispánica en Londres escribe a Felipe III el 9 de mayo de 1614, en la que le da cuenta del estado religioso de la isla, después de décadas de represión (Tobío 1987: 8). Según sus cuentas, Inglaterra (sin Escocia e Irlanda) tiene tres millones seiscientos mil habitantes, de los cuales trescientos mil son recusantes (católicos que no juraron el Acta de Supremacía), seiscientos mil son criptocatólicos (esto es, ciudadanos que juraron por miedo a las represalias pero siguen practicando la antigua fe de modo privado), otros novecientos mil son indiferentes (pero ven con buenos ojos al catolicismo), un millón doscientos mil son anglicanos y seiscientos mil son puritanos-calvinistas.

3. El exilio de las Islas Británicas, y especialmente de Irlanda, es uno de los procesos de mayor calado sociológico de la temprana Edad Moderna, cuyas causas y desarrollo ha estudiado O'Scea (2015): se estima que desde el último tercio del siglo xvi hasta 1700 emigraron al continente, 
La respuesta del papado y de los reinos católicos al cisma anglicano estuvo en muchas ocasiones inspirada o alentada por las propuestas de estos expatriados, que pautaban una hoja de ruta más o menos unitaria (y realista) según los momentos. Aunque se trata de un discurso que se podría denominar del exilio o de la resistencia - porque estuvo también activo entre los disidentes que vivían en las islas-, en estas páginas me voy a centrar en el primero de los sentidos. La historiografía contemporánea suele fijarse en la labor de los prohombres de este movimiento, tales como William Allen, Robert Persons, Edmund Campion o Richard Verstegan. ${ }^{4}$ Pero conviene observar también el devenir de los exiliados de menor relevancia para apreciar el hondo calado de ese discurso en el conjunto de los disidentes y en los lugares donde recalaban.

Para el caso de Irlanda, Holloway y Wray (2016) han estudiado el testimonio de dos mujeres católicas muy diferentes, Mother Browne y Lady Ann Fanshawe, que salieron de la isla a mediados del siglo XviI para vivir en Castilla, y cuyos escritos reflejan una particular experiencia del exilio. En primer término, Browne nos relata, en su History of the Irish Poor Clares (c. 1668), el viaje y la vida de las clarisas irlandesas en España. Por otro lado, en las memorias de Fanshawe, su autora tiene una clara conciencia de estar siendo acogida por los castellanos. En ambos casos, según la investigación citada, la idea de la persecución religiosa y del exilio se convierte en un marco especialmente propicio para la expresión literaria de ambas mujeres.

En busca de testimonios semejantes, he dirigido mi atención a la producción escrita de los colegios del exilio, que generaron a lo largo de los siglos un enorme corpus documental, con papeles escritos en inglés, en latín y en la lengua vernácula del lugar de acogida.

\section{Escribir desde los colegios del exilio}

Durante los años de mayor represión del papismo — los del reinado de Isabel I-, aquellos que no aceptaron las propuestas de la Reina Virgen pudieron mantener sus creencias de forma clandestina gracias a la existencia de los colegios del exilio. ${ }^{5}$ Estos colegios, proyectados al modo de los colleges de Oxford, se establecieron a partir de 1568 en Flandes, en el noroeste francés, en Roma y en Castilla,

como mínimo, 175 mil irlandeses, de los que 120 mil eligieron como destino los territorios de la Monarquía Hispánica.

4. De entre la bibliografía reciente sobre estos recusantes conviene destacar el balance bibliográfico que se plantea en los trabajos que editan Kelly y Royal (2016). Y para la violencia que ejerció Inglaterra sobre los católicos irlandeses, que motiva (entre otras causas) el exilio analizado en este trabajo, véase Corish y Millet (2005) y la síntesis histórica de Hsia (2010: 114-120).

5. Para una visión panorámica sobre estos colegios véase Burrieza (2002); y, más en concreto, sobre los colegios de ingleses de Valladolid y Sevilla, centros clave para entender el exilio inglés en Castilla, véase Burrieza (2000) y Murphy (2012). Sobre los colegios de irlandeses, véase las notas posteriores. 
y durante varios siglos fueron los únicos centros dedicados a la formación de los católicos de lengua inglesa. Se distinguían según la nación de sus integrantes: había por eso colegios de ingleses (en los que vivían también los galeses), de escoceses y de irlandeses. Estos alumnos, después de unos años de preparación $\mathrm{y}$, en muchos casos, después de recibir la ordenación sacerdotal, regresaban a las Islas Británicas para sostener la fe de sus compatriotas. ${ }^{6}$

En este trabajo pretendo centrar mi análisis en los escritos de los colegios de irlandeses establecidos en Castilla, cuyos archivos fueron a parar al principal y más longevo de todos ellos, el establecido en la ciudad del Tormes junto a la vieja Universidad salmantina. El Real Colegio de san Patricio de Nobles Irlandeses de Salamanca fue fundado en 1592 y desarrolló su labor hasta la guerra civil española (aunque subsistió hasta 1951). ${ }^{7}$ En esos cuatrocientos años varió su protagonismo dentro del mapa político y religioso de Europa, según las circunstancias de cada época, pero mantuvo siempre su identidad original. Para el interés de esta investigación, conviene centrar la mirada en las primeras décadas de su andadura. En 1606, a los pocos años de su fundación, el colegio aparece ya reseñado en la Historia de las Antigüedades de la ciudad de Salamanca de Gil González Dávila (Cuart 1994: III, 538-539), que nos ofrece de manera sintética una imagen completa de su naturaleza y de sus fines:

En el año M. D. XCII se fundó el Colegio de los Irlandeses, dedicado a S. Patricio Obispo, padre de la Cristiandad de Irlanda y sobrino de S. Martín Turonense. Fundose con el favor del Rey Filipo II, mandando por sus cartas a la ciudad y universidad de Salamanca amparasen a los que venían perseguidos y desterrados por sustentar la fe de su patria y de sus padres, y por aprender y sacar armas de esta escuela para poder contrastar al enemigo común de la Iglesia, haciendo voto de ir a predicar la ley evangélica a los otros irlandeses, sus hermanos, ofreciéndose al martirio por la salud de sus almas. Gente que por muchos títulos merece ser acorrida, por ser de diferente nación y sustentar tan católico y pío intento.

Desde finales del Quinientos y hasta 1700 se ponen en pie treinta colegios destinados a la formación de irlandeses en toda Europa. Y, entre todos ellos, el

6. Esta red de colegios recibió el apoyo institucional y económico de la Corona española, que sufragó también las ayudas de costa de los viajes de regreso a las islas —más conocidas como «viáticos»— tanto para desarrollar la Misión de Inglaterra como la Misión de Irlanda. Para esta última, y para la proyección social de los irlandeses en España, se deben consultar los resultados de las investigaciones dirigidas por Enrique García Hernán en el CSIC (<www.irishinspain.es>), así como la Base de Datos de la Misión de Irlanda (<http://digital.csic.es/handle/10261/64240>), y las investigaciones de la doctora Bravo Lozano.

7. La reciente monografía de Álvarez Rodríguez (2016) sobre este colegio ofrece una visión panorámica del papel desempeñado por esta institución a lo largo de los siglos. 
de Salamanca — junto con el de Madrid (1629-1937) — vino a ser el que tuvo mayor relevancia en Castilla y el que permaneció en funcionamiento durante más tiempo, hasta el punto de que su archivo fue recibiendo la documentación de los colegios de irlandeses que iban cerrando, como el de Valencia (16281680), Sevilla (1612-1767), Santiago de Compostela (1605-1769) o Alcalá de Henares (1630-1785). ${ }^{8}$

Poco después de que los primeros Catholic Relief Acts permitieran a los católicos establecer de nuevo centros de formación religiosa en Irlanda, se fundó al norte de Dublín, en la localidad de Maynooth, el St Patrick College (1795), que fue fundado como National Catholic Seminary of Ireland. Este centro fue asumiendo, paulatinamente, la labor de los colegios del exilio. Y cuando se desmanteló el último colegio de Castilla, el de Salamanca, la Universidad a la que estaba adscrito envió al archivo de Maynooth ${ }^{9}$ todos sus documentos, pero conservó una copia de los mismos. El investigador actual puede encontrar en el Archivo de la Universidad de Salamanca — sección irlandeses (AUSA_IRL) — cientos de escritos a partir de los 25.517 negativos resultantes de la reproducción. ${ }^{10}$ Entre ellos encontramos edictos, cartas, inventarios, títulos de propiedad, cuentas, recibos, etc. Dentro de este maremágnum, pude distinguir un corpus específico de textos corográficos que captó rápidamente mi atención por la cantidad de escritos que se habían conservado, porque estaban redactados en castellano, porque su contenido conseguía superar el horizonte meramente burocrático del resto de documentos y porque manifestaban cierta pretensión literaria. Estas obritas, en suma, podían hablarnos de la vida cultural y de los intereses de aquellos colegiales y mostrarnos cómo se construía el relato de una nueva Irlanda desde el exilio, una información relevante desde la perspectiva de los estudios sobre la configuración simbólica del espacio geográfico en las letras áureas. ${ }^{11}$

8. Para conocer la realidad de los colegios irlandeses en España se deben consultar las monografías de Recio (1996 y 2002), O’Connell (2001), García Hernán (2006 y 2012) y Álvarez Rodríguez (2016), principalmente. Para entender su relación con el Santo Oficio, y por extensión para cualquier aproximación sobre su influencia religiosa, véase O’Connor (2016). En la Biblioteca General Histórica de la Universidad de Salamanca se custodian también más de doscientos impresos con el ex libris del Real Colegio de san Patricio de Nobles Irlandeses. Puede consultarse el micrositio de la Biblioteca dedicado a este colegio y el inventario manuscrito de la biblioteca del colegio de los irlandeses, confeccionado a finales del siglo XviII: el Ms. 606 (fols. 55-87) conservado en USAL BG.

9. Se trata del llamado «Salamanca Archive», depositado actualmente en la Rusell Library del St Patrick's College de Maynooth: <www.calmview.eu/StPatricksCollege/CalmView/>.

10. Todo apunta a que la labor de microfilmado y el traslado de los documentos no se hizo de forma muy coordinada. El fondo actual salmantino está desordenado y es razonable pensar que no se conserva copia de todos los documentos que poseía el colegio. Además, en Salamanca se conserva copia de documentos que no están en Maynooth.

11. En la línea de los trabajos que edita Geisler (2013). 


\section{Un espacio geográfico, literario y político}

Estas descripciones se deben leer en el contexto de la relación de Irlanda con la Corona española y el apoyo que esta última ofreció a los líderes gaélicos en su lucha contra «la pérfida Albión». A comienzos del siglo XVI, Irlanda era un feudo pontificio que pertenecía como señorío al monarca inglés; un gobierno que, en verdad, se limitaba a un territorio pequeño en el entorno de Dublín y a unas pocas ciudades, porque los jefes rurales, tanto los gaélicos como los anglonormandos, eran independientes. Después de la ruptura de Enrique VIII con Roma, el parlamento irlandés consintió que la isla pasara a ser de soberanía inglesa. En 1541, Enrique se proclamó rey de Irlanda e impuso las leyes británicas en la isla vecina. Pero un grupo relevante de irlandeses no aceptó pacíficamente estos cambios y, ya con Eduardo VI, parecía claro que no estaban dispuestos a admitir la pérdida del catolicismo.

En esta pugna, su principal aliado contra la tiranía inglesa era la Monarquía Hispánica, por el protagonismo de España en la lucha contra la Reforma y por su posición de liderazgo internacional. Pero existía otra razón, que fue repetida ad infinitum por los apologetas de la causa irlandesa en escritos de todo género: España e Irlanda (Iberia e Hibernia) habían sido cristianizadas por el Apóstol Santiago y por sus venas corría la misma sangre. Según afirman las tradiciones gaélicas — que se remonta en este punto al Libro de las invasiones (s. XI)—, Milesio, el hijo de Breogán, llegó a Irlanda desde Galicia con la última inmigración celta del siglo XII a. C., y sus hijos conquistaron la isla y establecieron una dinastía que reinó hasta la llegada de los normandos en el siglo XII. Andando el tiempo, en los albores de la Edad Moderna — en este momento crucial para la supervivencia de Irlanda - los líderes gaélicos se declararon súbditos del rey castellano en virtud de esta vinculación, que resultó clave para el discurso del exilio y estará vigente en el entorno de los colegios durante varios siglos, como veremos más adelante.

La actualización de esta leyenda obedecía a una praxis tendenciosa que pretendía influir en la voluntad regia, sobre todo a comienzos del siglo XVII, pero fue tan insistente que la propia historiografía española se hizo eco de sus argumentos. Esteban de Garibay, por ejemplo, en su temprano Compendio historial (1571), afirma que «el rey Brigo [Breogán] envió gentes a poblar la isla de Irlanda [...], llamada primero Hibernia, cuyos naturales [...] siempre de padres a hijos han conservado tan eficazmente esta tradición en memoria que, en la era presente, se precian y jactan ser española su origen y dependencia». ${ }^{12}$ Entre los impresos promovidos por el colegio de los irlandeses de Sevilla, en la Breve relación de la presente persecución de Irlanda (1619), se explica que «a esta, pues, descendencia y sangre de españoles (...) se debe atribuir la constancia

12. Según el ejemplar de la USAL BG/10116, vol. 1, lib. IV, cap. VIII, p. 89. 
tan insigne de los irlandeses, en haberse conservado siempre la pureza de la fe católica, recibida al principio de boca del mismo glorioso apóstol y patrón de España, Señor Santiago, que después de haberla plantado acá, fue a predicarla a los españoles de allá de Iberia». ${ }^{13} \mathrm{Y}$ pocos años después, Philip O’Sullivan Beare (1590-1666) - un líder gaélico de rancio abolengo que fue enviado a Galicia en 1602 y fue uno de los primeros alumnos del colegio de Santiago de Compostela-, después de servir al rey de España como soldado, colaboró en la configuración de la identidad irlandesa con obras como la Historiae Catholicae Iberniae Compendium (Lisboa, 1621), que sintetiza la interpretación historiográfica de los católicos irlandeses en su conflicto con la Inglaterra anglicana. Dicha obra comienza con un primer libro dedicado a la descripción de la isla y a su origen hispano, en los términos comentados. ${ }^{14}$

Aunque los reyes de España no tomaron muy en consideración este arcano derecho sucesorio, el hecho es que, tanto por razones de orden religioso como por razones de Estado, la Monarquía Hispánica alentó la causa irlandesa a través de la diplomacia, la intervención armada y la acción cultural. Pero Irlanda estaba situada en la frontera norte y a mediados del siglo xvi no existían mapas del interior de la isla, ni se tenía un conocimiento certero de su geografía. Si exceptuamos los puertos comerciales, bien conocidos desde la Edad Media, no se contaba con descripciones geográficas solventes del resto de la isla. Los atlas más difundidos en la segunda mitad del Quinientos — los del viejo Tolomeo o los modernos de Ortelius o Porcacchi (figura 1) - ${ }^{15}$ ofrecen una información mínima, ${ }^{16} \mathrm{y}$ hemos de esperar hasta bien entrado el siglo xviI para poder disponer de un mapa tan completo como el de William Blaeu. ${ }^{17}$ Irlanda era, por tanto, terra incognita, situada en las brumas del limes septentrional, que a los ojos de la cultura hispana se presentaba como un lugar agreste y misterioso, donde la imaginación debía completar el espacio vacío de los planos.

13. Según el ejemplar de la BNE R/12223, p. 15. Actualizo la ortografía. Este ejemplar conserva dos marcas donde la crónica incluye una oración a Dios en solicitud de auxilio (pp. 43 y 47). Es posible, por tanto, que dichos impresos sirvieran para la plegaria personal o comunitaria.

14. Según el ejemplar de la USAL BG/31284, pp. 2-13. Sobre este autor y esta obra deben conocerse los trabajos de Rey (2002) y Morgan (2002).

15. Tengo presente la descripción realizada por Ortelius en 1570 (USAL BG/10802, n. 6) y la que publicó Porcacchi en L'isole piu famose del mondo (figura 1), que gozó de una asombrosa difusión en esa centuria.

16. En el último tercio del siglo XVI, Inglaterra se preocupó por fijar sus cánones cartográficos en atlas de gran detalle descriptivo, como la Descriptio Angliae de Christopher Saxton, un proyecto amparado por la reina y por William Cecil, su mano derecha (tengo presente el ejemplar de 1579 de la Real Biblioteca, sign. IX/7223 [1]), que, sin embargo, no incluye la geografía irlandesa.

17. En verdad, como ha expuesto Recio (2003: 39-40), no será hasta la década de 1650 cuando se llegue a tener un conocimiento real del interior de Irlanda. 


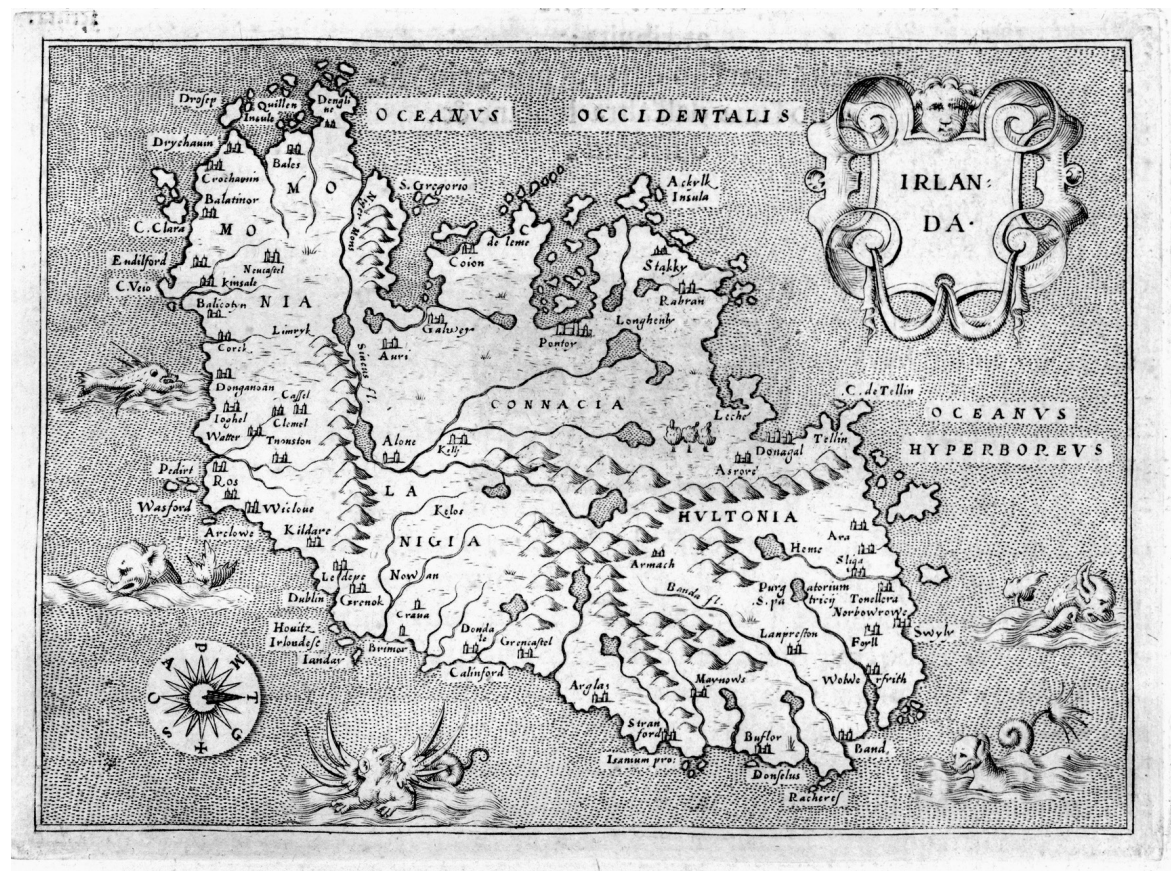

Figura 1

Irlanda - Hibernia. Tommaso Porcacchi, Lisole piu famose del mondo (Venecia: Simon Galignani, 1590) (USAL BG/30379, p. 12).

A pesar de estas deficiencias, Felipe II tenía que gobernar con información fiable. Por ello, envió a soldados y a gente plática para reconocer la isla y conseguir así informes con los que estudiar la viabilidad de la colaboración española en este conflicto. ${ }^{18}$ Las fuentes clásicas, tanto griegas como latinas, describían ya a los habitantes de Hibernia como gente salvaje, bárbara e incivilizada. Y las relaciones de los enviados filipinos parecen insistir en esta misma línea. Diego Ortiz de Uriçar, por ejemplo, expone a su Majestad en 1574 que los gaélicos son gente «holgazana, enemiga de trabajar, y así lo que siembran cuatro lo vienen a comer ciento, porque el que más puede hurtar al vecino se tiene por más hombre». ${ }^{19}$

18. Para la implicación de la Monarquía Hispánica en el «problema irlandés», véase principalmente a García Hernán (2000) y Recio (2003), de quien procede esta información sobre las descripciones de la isla y sobre los enviados filipinos (Recio 2003: 39-45 y 59-68).

19. «Relaçión que haze el capitán Diego Ortiz de Uriçar de lo que vio en Yrlanda, diola a Su Md. en Madrid a 26 de junio, 1574", Archivo General de Simancas, E-Negociaciones con Inglaterra, leg. 828, fol. 106 (apud Recio 2003: 62). 
Esta imagen contrasta vivamente con las descripciones compuestas en los colegios del exilio, que llevaron a cabo una importante labor de acopio y traducción de referencias clásicas, y proyectaron una nueva imagen de la isla a través de la composición de descripciones ideales de Irlanda, con el fin de favorecer la benevolencia de los monarcas españoles y de la sociedad castellana en general hacia la causa de Irlanda, ya que, a fin de cuentas, eran los castellanos los que sostenían y daban cobijo a estos disidentes.

Una de las descripciones conservadas en el archivo de Salamanca, la titulada «Del nombre, sitio y clima de la Isla de Irlanda, temperamento, fertilidad de su tierra y condición de sus naturales», puede servir de ejemplo para describir este afán de idealización del lugar. ${ }^{20}$ Después de evocar el origen mítico de Irlanda —recuerda aquí la llegada de los pobladores españoles desde Galicia—, el autor otorga a la isla el calificativo de "milagrosa», "por sus grandes maravillas y cosas prodigiosas que la naturaleza ha producido en ella». La descripción geográfica y climatológica es también idílica: «Su temperamento es de los mejores y más dulces de todo el reino británico, causa de gozar de la felicidad y serenidad de mejor cielo». De esta forma, «descubre también la naturaleza de su temple el vivir los hombres muchos años sin tener necesidad de médicos». De igual modo se describen los campos y la geografía del lugar: la tierra está «bien cultivada [y] no hay baldías», es "fértil de pan y frutas» $\mathrm{y}$ "sus pastos son muchos y los mejores de Europa, donde apacientan sus ganados con tanta abundancia que muchas veces para que no revienten los apartan de ellos», junto a otras bondades alimenticias y cinegéticas. Al describir a los naturales, presenta a los irlandeses como "gente de buena disposición, de rostros claros, de cuerpos bien proporcionados, robustos y en sufrir trabajos señalados. Son templados en su comer y beber. Gustan de música, principalmente de un instrumento de hechura y forma de arpa, tan dulce en su consonancia que a las mismas fieras [...] las necesita a meterse por los lazos y redes del cazador astuto, por gozar del veneno dulce que las mata». En suma, todo un ideal de cortesanía renacentista: «Son también inclinados al ruido de armas, o al sosiego de las letras, buscando tan solamente la posteridad de nombre y fama: apetecen libertad, y muy pocos, si la necesidad no fuerza, aprenden artes mecánicas. Ejercítanse mucho en correr a pie y a caballo en cazas y monterías, por la mayor parte de su grandeza y nobleza».

Estas descripciones se podrían adscribir al género de la corografía renacentista, tan popular en la Edad Moderna, que sirvió como complemento de la historiografía canónica al describir localizaciones concretas e interesarse por detalles y anécdotas. Este tipo de escritura corográfica sirvió a los Habsburgo para dar cuenta de sus dominios y a las corporaciones municipales para mostrar las virtudes de su ciudad y adquirir mayor reconocimiento. Tenía por tanto una finalidad ad extra, ya que servía para proyectar hacia fuera los intereses del rey

20. Sobre este escrito, véase la relación de documentos que se describe a continuación, en el n. 9 . 
y de las oligarquías urbanas. En nuestro caso, como hemos visto, esa finalidad ad extra sería la propagación de una determinada visión de Irlanda que persigue ganar la adhesión de los espańoles para la causa. Pero los escritos corográficos presentan también, como ha estudiado Kagan (2002: 147), una función ad intra, ya que servían para «instruir a los habitantes de un lugar concreto acerca de cómo pensar sobre la comunidad en que vivían» y, en el caso de nuestros colegiales — que es la lectura que más nos interesa aquí-, para mantener una peculiar reflexión sobre su patria y sobre el sentido de su exilio, para fortalecer sus convicciones, establecer lazos de sintonía cultural y religiosa con los lugares de acogida, y — cómo no, si nos encontramos en el marco de la cultura celtapara mitigar de algún modo la nostalgia por el hogar perdido.

\section{Las descripciones de Irlanda en el archivo salmantino}

En mi consulta directa de los fondos del Archivo de la Universidad de Salamanca creo distinguir al menos nueve descripciones diferentes escritas en español, y varias copias de algunas de ellas. Se muestran aquí según el orden de aparición en dicho archivo. Al pie del título se incluye la signatura: AUSA_IRL, $\mathrm{n}^{\circ}$ de carpeta, $\mathrm{n}^{\circ}$ de las imágenes correspondientes. Después se ańaden unas observaciones sobre su datación, su composición, e incluso sobre la mano que compone o copia el texto.

Estos fondos, como se ha indicado, son microfilms de los originales, se conservan de forma desordenada, y su estado material es muy precario. A la espera de que futuros investigadores elaboren un corpus más completo -incluyendo los registros de Maynooth y de otros archivos-, se ofrece a continuación un conjunto de textos que es suficientemente significativo para un primer trabajo exploratorio como el presente:

[1] «De la calidad y condición de la isla de Hibernia» (AUSA_IRL, carpeta 2, 241244). Fechado en septiembre de 1616, letra A. Forma parte de un escrito dirigido "Al Reverendo Cristóbal de Framín», que consta de varias partes: Presentación (240); cap. 1, «De la calidad y condición de la Isla de Hibernia» (241-244); cap. 2, «De la cristiandad en Irlanda» (244-249); cap. 3, «Cómo florecieron allá las letras y la fama que en ellas alcanzan sus hijos» (249-252).

[2] «De algunas cosas raras que hay y ha habido en Irlanda» (AUSA_IRL, carpeta 2, 264-275). Escrito c. 1607, letra B. Es un trabajo inconcluso, con tachaduras. Se edita en el apéndice de este artículo.

[3] «Del reyno de Irlanda, su Iglesia y cosas concernientes a ella» [3.1] AUSA_IRL, carpeta 3, 1-3. Escritura del siglo XviII, letra D.

[3.2] AUSA_IRL, carpeta 3, 4-5. Escrito c. 1607-1616, letra B.

[4] «Breve relación de Irlanda y de tres diferencias de irlandeses que hay en ellas» [4.1] AUSA_IRL, carpeta 3, 37-43. Escritura del siglo xviII, letra D. 
[4.2] AUSA_IRL, carpeta 3, 44-47. Escrito c. 1611, letra C.

[4.3] AUSA_IRL, carpeta 3, 81, 83-101. Escritura del siglo xIx, letra E.

[4.4] AUSA_IRL, carpeta 4, 60-83. Escritura del siglo XIX, letra E (una copia distinta a 4.3. pero de la misma mano).

[5] «La descendencia de los irlandeses con una breve descripción de la isla de la Ibernia, comúnmente llamada Irlanda, sacada de autores antiguos y graves» (AUSA IRL, carpeta 46, 351-352). Escritura del siglo xvII; se completa con un capítulo 2 titulado «De lo eclesiástico» (353).

[6] «Breve descripción del Reyno e Isla de Irlanda y sus cosas» (AUSA_IRL, carpeta 46, 354-372). Escritura del siglo XVII.

[7] «De cosas maravillosas y milagrosas desta tierra» (AUSA_IRL, carpeta 46, 389390). Parece parte de un escrito mayor, junto con el n. 6 y con otros papeles ilegibles que figuran entre ambos documentos.

[8] «Las excellencias del Reyno de Ibernia alias Irlanda» (AUSA_IRL, carpeta 46, 391). Formato pliego, doblado en forma de cuadernillo, que presenta un texto corográfico en los cuatro folios interiores, sin pérdida de texto.

[9] «Del nombre, sitio y clima de la isla de Irlanda, temperamento, fertilidad de su tierra y condición de sus naturales» (AUSA_IRL, carpeta 46, 395-399). Es el primer capítulo de un escrito de dos capítulos; el segundo lleva por título: «De la successión de los reyes de Hibernia» (399-407).

[10] «Breve descripción de Irlanda y su estado antiguamente y agora» (AUSA_IRL, carpeta 46, 408-426. Bajo este título, el documento se subdivide en varios capítulos: cap. 1, «De sus nombres, grandeza, sitio y calidad» (408-411); cap. 2, «De las cosas raras que se escrive de las alabanças de Irlanda y casi proprias a ella» (411420); cap. 3, «De donde se toca el estado de la Iglesia en Irlanda hasta nuestros miserables tiempos» (422-426).

Para confeccionar esta relación, he tenido en cuenta aquellos textos que ofrecían un mayor sentido descriptivo, de forma que he descartado los más narrativos, como los martirios o los de carácter noticiero. Sin embargo, aparte de considerar estas premisas, no es fácil establecer unas fronteras genéricas claras.

En primer término, destacan las descripciones propiamente dichas, cuyas claves he expuesto en el epígrafe anterior al comentar el texto titulado «Del nombre, sitio y clima de la isla de Irlanda» (n. 9), que es semejante a los escritos con el número 1, 3, 5 y 6. El n. 5, por ejemplo, dedicado a «La descendencia de los irlandeses con una breve descripción de la isla de la Hibernia, comúnmente llamada Irlanda», es una composición que, como se afirma al comienzo, está «sacada de autores antiguos y graves»: de ahí que en los primeros párrafos siga — y cite- el capítulo seis de la historia de Irlanda de Giraldo Cambrese para hablar de la naturaleza ideal de la isla, y el capítulo dieciséis para subrayar el origen español de los gaélicos a raíz de la llegada del rey Milesio a la verde Erin. Después prosigue, de 
la mano de Paolo Giovio, para insistir en la bondad del clima y la fertilidad de los campos, y finaliza, en los mismos términos, citando a Mercator.

En estas descripciones encontramos también, como ya se ha visto de forma tangencial, una apelación a las maravillas de Irlanda, en el sentido de tierra «milagrosa» donde abundan los prodigios, materia que llega a constituir el asunto central de otros escritos, como el número $2,7,8$ y 10 , hasta el punto de que podrían formar un grupo específico de relaciones de prodigios. De todas ellas, la más relevante, por su calidad y extensión, es la n. 2, que analizo con más detalle en el epígrafe siguiente.

\section{Los prodigios de Hibernia: «De algunas cosas raras que hay y ha habido en Irlanda»}

El escrito más extenso dentro del grupo dedicado a los prodigios de la isla lleva por título «De algunas cosas raras que hay y ha habido en Irlanda» (n. 2). Se trata de una relación de lugares que destacan por su carácter milagroso y pretende mostrar cómo la geografía irlandesa está impregnada de un sustrato católico que se revela en la propia naturaleza (islas, fuentes, lagos, ríos, etc.) o en algunos lugares de marcado sentido religioso (cruceros, cementerios, etc.). En estas páginas propongo un primer acercamiento a dicho texto, en la línea de los estudios sobre el estatuto de lo fantástico en la literatura aurisecular. ${ }^{21}$ Por ello, mi interés se centrará en analizar sus conexiones con la cultura literaria española del momento y no en su valor como documento historiográfico. En el apéndice se ofrece una transcripción del texto completo. Afortunadamente, el autor numeró los párrafos principales del escrito, de forma que se pueden citar los distintos apartados de la composición de manera directa (con el símbolo tipográfico de párrafo $\$$ ). Debido al carácter exploratorio de esta lectura, sólo apuntaré aquí sus notas más características, de forma esquemática.

\section{Contenido y composición}

Los prodigios que se muestran en esta descripción están destinados a fortalecer los principios católicos en pugna con los postulados protestantes: el purgatorio, los sacramentos, la devoción a la Virgen María, etc. Asimismo, refuerza numerosos elementos de la religiosidad tradicional criticados por la Reforma, tales como las peregrinaciones, la penitencia, la devoción a los santos o el ayuno. Esta defensa de la ortodoxia se completa con un ataque explícito al hereje inglés $(\$ 7)$, que se presenta como un personaje incrédulo y arrogante, cuya falta de fe le lleva a sufrir

21. En el marco de las investigaciones que recogen Arellano (2003), Salvador (2004) o Insúa y Peres (2009). Para entender el contexto de interpretación de lo prodigioso en la temprana modernidad véase Vega (2002). 
el efecto contrario de dichos prodigios. Su veracidad es confirmada además por algún «testigo de vista» que informa directamente al autor $(\$ 3,10,14,32)$.

El escrito está inconcluso, como si fuera un documento de trabajo, a juzgar por el estado en que se encuentran las últimas páginas. Está compuesto como una peculiar combinación de fuentes cultas y de motivos de raíz popular. Entre los autores citados encontramos a Beda el Venerable ( $\$ 1)$, Hector Boece $(\$ 15)$, Giraldo Cambrese $(\$ 34)$ o Sabellico $(\$ 40)$. Estas fuentes dotan al texto de una autoridad que refuerza la credibilidad de todo el discurso. El uso de estas autoridades es un recurso habitual en las descripciones de Irlanda ya que todas ellas parecen compartir un conjunto reducido y común de referencias. La comunidad irlandesa debió de establecer dicha inventio ideal de autoridades en busca de un fundamento intelectual para su causa. El modo en que se utilizan aquí nos permite suponer que estamos ante el borrador de algún tipo de ejercicio académico. En este sentido, llama la atención la coexistencia de estas referencias de origen libresco y el tipo de prodigios que se narran, que son más propios de la literatura popular. La mayoría muestra un punto de ingenuidad y extravagancia que atenta contra las disposiciones postridentinas que pretendían depurar el santoral y las devociones populares de toda tradición espuria. Esta tensión ha sido descrita muchas veces dentro de la propia cultura religiosa del momento - pienso por ejemplo en los análisis de Caro Baroja (1985: 95-124)—; aun así, sorprenden en la pluma de un profesor o un alumno de estos colegios.

El texto ha sido escrito en lengua castellana por un irlandés, y está destinado a ser leído por irlandeses. El autor se refiere a la isla como "nuestra Irlanda» $(\$ 10)$, «nuestra patria» $(\$ 22)$ y «nuestro reino» $(\$ 40)$; nombra a san Patricio como «nuestro insigne Patriarca y apóstol san Patricio» (\$27), y todas las aclaraciones léxicas están orientadas en este mismo sentido: «un báculo que los nuestros llaman bachal, (\$28), etc. Conviene destacar también la compleja galería de topónimos que unas veces muestran una fuerte castellanización — «san Molazo» por st Mullins $(\$ 9)$, por ejemplo—, otras se trata de nombres que figuran en la documentación castellana de la época con ese mismo término — «Ultonia» por Ulster, "Kilkenia» por Kilkeny, etc.—, y otras se asemejan al inglés original — como «Waterfor» por Waterford $(\$ 42)$-; unas variaciones que ponen de manifiesto que la composición se ha realizado en un entorno bilingüe. No se descarta por ello la hipótesis de que la redacción de estos escritos sirviera como medio para el aprendizaje de la lengua española o como ejercicio de escritura académica, motivo por el cual la mayoría de los testimonios nos han llegado llenos de correcciones.

\section{Un espacio religioso}

El escrito tiene una finalidad religiosa, pero también política, ya que es la propia tierra la que se muestra como católica. De esta forma, se opera una identificación entre territorio, religión y causa política. Se ha ampliado, por tanto, el uso tradicional de los relatos de prodigios de origen medieval, que eran un arse- 
nal de motivos para la homilética o para la literatura popular devota, en favor de un discurso progaélico. Y este es un punto capital de las descripciones de Irlanda, porque el cisma anglicano influyó de forma muy distinta en el discurso del exilio inglés y del irlandés. Los católicos ingleses se plantearon el difícil dilema de la lealtad a la corona, con soluciones diversas según los casos y los momentos (durante cientos de ańos, de hecho, ser católico parecía incompatible con ser inglés); pero los católicos irlandeses, en cambio, renegaron en mayor medida de la influencia política y religiosa de Inglaterra y procuraron tanto la defensa armada como la mitificación de su propio espacio geográfico; un espacio que, junto a la causa religiosa, eran las señas de identidad de su rebeldía.

En este sentido, conviene señalar que todos los santos citados son santos patrios, y que aparecen vinculados a algún hecho maravilloso localizado en Irlanda, como san Patricio $(\$ 1-2,28)$, san Columbano $(\$ 20)$, santa Brígida ( $\$ 34-$ 35 ) o san Segundino ( $\$ 47)$. Al hablar de estos santos y del relato de sus milagros nos volvemos a encontrar con el problema que apuntaba anteriormente: el autor no ha sido sensible al espíritu de purificación de las prácticas devocionales que se operó a partir del Concilio de Trento. Pero se trata de un uso menos desviado del que encontramos en el resto de prodigios, ya que el flos santorum castellano postridentino incluyó la biografía de los santos irlandeses más destacados; ahora bien, no aparecen en una posición tan destacada como en esta relación sino dentro del capítulo dedicado a los «santos extravagantes», esto es, aquellos que estaban fuera del breviario y del misal de Trento, aquellos cuya tradición devocional se consideraba menos fiable o documentada. ${ }^{22}$

Pero lo más relevante, como decía, es la construcción de un discurso que presenta a Irlanda como tierra de santos. Desde el último tercio del siglo xvi los líderes de la causa irlandesa están proyectando la vida de san Patricio como una de las banderas de su lucha política y religiosa. Se escriben por entonces algunas de las hagiografías del santo más conocidas, como la de Richard Stanihurst publicada por Plantino en 1587. ${ }^{23}$ A comienzos del Seiscientos, el inglés Peter Lombard compone De regno Hiberniae sanctorum insula commentarius en apoyo de la causa de Irlanda: una suerte de historia eclesiástica que presenta a la verde Erin como tierra de mártires y santos. ${ }^{24} \mathrm{Y}$ poco tiempo después hace su aparición un personaje capital para el rearme intelectual gaélico, el citado Philip O’Sullivan,

22. Véase el primer volumen del Flos sanctorum (1578) de Alonso de Villegas, en su apartado de "santos extravagantes», según la edición de 1621 que tengo presente (USAL BG/54389): santa Brígida (fol. 422r-v) y san Patricio (fol. 435v-r). En el santoral de Ribadeneyra, en cambio, ya no encontramos a san Patricio (en las primeras ediciones), pero sí a santa Brígida (tanto en la ed. de 1604 como en la ed. 1609, USAL BG/48784, pp. 137-140).

23. Tengo presente el ejemplar de la USAL BG/28457. Sobre la participación de Stanihurst en el devenir de la causa de Irlanda, véase Lennon (1981).

24. Aunque estaba compuesta en torno a 1600, no se publicó hasta 1632 . Tengo presente el ejemplar de la USAL BG/29347. 
que publicó su Historiae Catholicae Iberniae compendium (Lisboa, 1621), en la que encontramos - junto a la descripción de Irlanda y a la exaltación del origen hispánico del pueblo gaélico ya citada - una traducción del viaje al purgatorio de san Patricio compuesta por Ramón de Perellós en el siglo XIV y una evocación de los santos gaélicos dentro de una crónica de la rebelión armada de los irlandeses contra Inglaterra (que incluye una historia de los colegios en el exilio).

La leyenda del purgatorio de san Patricio que se apunta en nuestro escrito es el resultado de una transmisión que supone, según don Martín de Riquer (1978: 57), «toda una excursión por las literaturas de Europa desde el siglo XII hasta el XVII». En 1189 el cisterciense irlandés Saltrey escribe el apasionante Tractatus de Purgatorio Sancti Patricii. Hacia 1190 María de Francia lo traslada al francés con el título de Espurgatoire Saint Patrice, y en 1397 el diplomático Ramón de Perellósy de Roda, vizconde de Perellós, traduce el Tractatus al catalán, con interpolaciones de su propia imaginación. Su Viatge al purgatori se traduce después al provenzal y en esta lengua se imprime en Toulouse en 1489. En el siglo XVII se vierte de nuevo al latín como parte del compendio de O'Sullivan. No se ha estudiado aún el modo en que dicho libro circuló por la Península Ibérica y por los colegios del exilio, pero el caso es que, a los pocos años de su publicación, Juan Pérez de Montalbán lo tradujo al castellano con el título de Vida y purgatorio de San Patricio, que vio la luz en Madrid en 1627 y gozó de un éxito arrollador, con más de media docena de ediciones en los diez años siguientes. Su lectura atrajo entre otros a Lope de Vega, que se basó en este librito para componer su comedia El mayor prodigio o el purgatorio en vida, también de 1627. De la misma forma interesó a Calderón de la Barca, que lo utilizó para escribir El purgatorio de San Patricio, una comedia que debió de componerse a finales de 1627 o principios de $1628 .{ }^{25} \mathrm{Al}$ año siguiente, O’Sullivan volvería de nuevo sobre la historia de san Patricio en sus Patritiana decas: sive libri decem, quibus de divi Patritii vita, purgatorio, miraculis, rebusque gestis (Madrid, 1629), que, junto con narrar los hechos prodigiosos del patrón de Irlanda, dedica varias páginas a la descripción y a la historia mítica de la isla. ${ }^{26}$

Esta labor de Lombard y O'Sullivan emula, en cierto modo, a la que realizaron Nicholas Sander o Robert Persons para la causa inglesa, y no solo la emula sino que perpetúa algunos de los motivos y microgéneros que estos últimos proyectaron, como la traducción y refutación de edictos anglicanos, la narración de las persecuciones o la importancia que se otorga a los colegios del exilio en todo el relato. Pero se distinguen de ellos en lo que la causa irlandesa tiene de peculiar: la vinculación original y mítica con España, la proyección de los santos patrios y el afán por describir la isla.

25. Para un recorrido crítico sobre este motivo en el teatro clásico español, véase el trabajo clásico de Profeti (1976) y a Carrizo (2002).

26. Tengo presente el ejemplar de la USAL BG/27885 (ff. 2r-4v). 
Los documentos analizados en el presente trabajo son ligeramente anteriores a estos tratados latinos. Sirven, por tanto, para advertir cómo se va conformando la construcción del discurso del exilio irlandés. Por otro lado, no cabe duda de que la resistencia irlandesa no se preocupó tanto como la inglesa de la traducción de sus obras más representativas. No existe, por ejemplo, un correlato irlandés de la Historia eclesiástica del cisma de Inglaterra (1588) de Ribadeneyra, pero debió de hacerse presente en la cultura castellana por otros caminos, merced a la difusión de los intereses irlandeses a través de los colegios y de textos como los que aquí se analizan. Una sintonía que nos ayudaría a explicar la fortuna que la historia de san Patricio gozó en tierras castellanas.

\section{Iberia-Hibernia}

A lo largo de este trabajo se ha valorado ya cómo los dirigentes de la causa irlandesa proyectaban de forma interesada la legendaria vinculación de los pueblos español y gaélico. Aunque en el escrito que estoy comentando —el n. 2 - no se cita la leyenda del rey Milesio, tampoco se deja de buscar una relación con España que, a fin de cuentas, es el lugar en el que se escribe la descripción. En el prodigio narrado en el párrafo $\$ 26$ se cuenta la inexplicable aparición de un frasco de oro en un río, que avisaba al señor del lugar de que alguien de su familia iba a fallecer: un milagro que se presenta como semejante al de la campana del convento de los dominicos de Zamora, donde se escucha el sonido de una campanilla cuando alguno de los monjes va a morir, de forma que todos puedan prepararse para el último viaje. Este es el único prodigio que se sitúa fuera de la isla y nos trae a la memoria un prodigio que fue popular durante los siglos XV-Xvir: la campana de Velilla de Ebro (Zaragoza), que fue la fuente de varias obras dramáticas y poéticas en el Siglo de Oro. ${ }^{27}$ Feijóo le dedica una extensa Disertación en su Teatro Crítico Universal (tomo Ix), donde recuerda otros casos semejantes que suceden en España, como el de la campana zamorana, y permite suponer que este escrito fue compuesto en el colegio de Salamanca, el más cercano a Zamora de todos los irlandeses.

Según se ha descrito en los últimos epígrafes, estos prodigios se pueden situar, tanto por sus motivos como por su retórica, en el horizonte de intereses de la literatura popular (relaciones de sucesos, de milagros, etc.) y es posible, por tanto, que fueran también del agrado de los espańoles.

\section{Las metamorfosis de Cervantes}

La localización septentrional de esta descripción era también del gusto de la literatura áurea hispánica. Para los hombres de la Edad Media, el entorno geográfico más exótico era el inmenso continente asiático, pero para los del último tercio

27. Como han estudiado Marcello (2006) y Domínguez (2001). 
del Quinientos y de los primeros compases del Seiscientos lo fueron las tierras del norte de Europa. En este sentido, conviene recordar que Cervantes eligió ese escenario para su Persiles por motivos estéticos, según la moda de su época. En dicha novela, Cervantes muestra también su interés por ciertos animales fantásticos que sufren algún tipo de metamorfosis, como el licántropo o las barnaclas, unos pájaros mitológicos que se originan a partir de la materia inorgánica (Persiles, lib. 1, cap. 12). Por suerte, ya ha sido desterrada la idea de que la aparición de estos seres en la narración cervantina no es más que una senil extravagancia del novelista, ya que «forman parte de uno de los debates que tuvo que abordar la ciencia natural del siglo XvI, a saber: si la materia tanto orgánica como inorgánica podía transformarse» (Lozano 1998: 162). Cervantes, por tanto, no hace sino estar en sintonía con los intereses de los lectores y de la ciencia de su tiempo. Estas ideas nos pueden servir también para contextualizar la aparición de las barnaclas en nuestra descripción, que explica el nacimiento de estas aves en el párrafo $\$ 36$. En el pasaje cervantino se cita como «barnacla» y en nuestro documento como «bernácula», en trascripción directa de la palabra barnacle, que es de origen inglés. ${ }^{28}$

\section{La literatura de viajes}

Con los datos de que disponemos no se puede establecer una relación clara entre nuestros escritos corográficos y la literatura de viajes de la época. Pero conviene dejar constancia, al menos, de ciertas semejanzas significativas. Por ejemplo, se puede advertir una sintonía entre las claves de interpretación expuestas en este trabajo y una obra paradigmática de este género, como es el Viaje del mundo (Madrid, 1614) ${ }^{29}$ de Pedro Ordóñez de Ceballos. En el capítulo 13 del primer libro, que trata «De la vuelta a España y viaje a Inglaterra y golfo de Dania y a Irlanda», el autor nos muestra su experiencia directa de la isla, al modo de los informadores de Felipe II: «De allí fuimos a Irlanda [...]. Es esta tierra muy fría y mísera, y pienso que la gente es la más blanca del mundo; no roja como la de Inglaterra sino blanquísca. Es gente dócil, amiga de servir y dar contento» (f. 29v). Una descripción que se completa poco después, en los siguientes términos: «nos hallamos sobre la isla de Hibernia, en el puerto de Siogo, donde nos hicieron mil molestias, porque es gente sin Dios, y al fin todo paró en llevarnos nuestro dinero» (ff. 29v-30r). Lo sorprendente del caso es que una persona que conoce de primera mano los lugares que describe incluye en su libro un capítulo titulado «En que se hace relación de algunas cosas maravillosas del mundo» (lib. III, cap. XIX):

En Bornia de la provincia de Mononia [Munster] hay dos bańos, el uno que el agua de él vuelve todos los pelos y cabellos canos y el otro quita todas las canas, y hay un lago con dos islas: en la una, en entrando hembra se muere. En Ul-

28. Para una comparación más exhaustiva de las apariciones literarias de la barnacla en la lengua castellana y la especulación científica sobre estos misteriosos animales véase Lozano (1998: 161-171). 29. Tengo presente el ejemplar de la USAL BG/10934. 
tonia [Ulster] hay otros baños en la cumbre de un monte, que crece y mengua cada día tres veces. Hay un lago que tiene dos islas; una tiene boca, y los que duermen allí ven visiones, y la otra es amena y apacible.

Para este viajero, semejante materia merecía un capítulo específico que coincide, tanto en los motivos como en los términos, con lo redactado en el colegio irlandés (véase por ejemplo $\$ 3,6$ y 28).

En esta primera lectura del escrito n. 2, en suma, se puede advertir cómo esta relación de prodigios se sitúa en la línea temática central del discurso de exilio irlandés y encuentra multitud de puntos de contacto con los intereses literarios de la Castilla del momento.

\section{La causa de Irlanda}

Como apéndice de este estudio, comentaré un documento dirigido al rey de España que presenta una especial relevancia para el discurso del exilio irlandés, la «Breve relación de Irlanda y de tres diferencias de irlandeses que hay en ellas» (n. 4). Incluye una breve historia de la isla y una relación de los irlandeses exiliados en Castilla que se dicen vasallos de su Majestad y que contiene casi un centenar de personas de distinto estado y condición.

La relación comienza con el siguiente punto de partida: «En el reino de Irlanda hay tres géneros de irlandeses, conviene a saber: antiguos, inglesados y mixtos». En primer término, "Los antiguos son los que descienden de los españoles, que ha más de dos mil ańos que ganaron aquel reino a los griegos y lo gobernaron con justas y santas leyes, ayudados de la doctrina y santidad de muchos santos milagrosos y doctos hombres que de ellos mismos salieron, hasta que entraron los dinamarcos».

Los mixtos son los que «se casaron con hijas de irlandeses antiguos [...], de manera [que] tienen tanto de la sangre irlandesa antigua como de la inglesa, y en la lengua, traje y costumbres se conforman con las antiguas», y los inglesados, naturalmente, son «los ingleses que no se casaron en Irlanda, ni emparentaron con irlandeses antiguos, ni tomaron la lengua, traje ni manera de vivir». Por supuesto, a comienzos del siglo XVII, estos «tres géneros de irlandeses conviven en una cosa que es ser católicos e hijos de la Iglesia Romana, pero difieren mucho de la manera de vivir [...] y en las inclinaciones naturales y deseos de tener príncipes y leyes a que se sujeten, que cada género de ellos apetece su natural». Y de aquí se derivan varias consecuencias prácticas, porque los irlandeses antiguos, "como descendientes de españoles, se quisieran gobernar por reyes de España como descendientes de ellos y tienen amor y afición a la nación española, como también odio y enemistad a los contrarios y en la agudeza de los entendimientos y valor en la guerra los imitan». Los irlandeses inglesados, en cambio, «siguen las inclinaciones de los ingleses y quisieran guardar sus leyes y manera de gobierno que de ellos trajeron y así el rey de Inglaterra les concediese libertad de conciencia o permitiese tener en sus casas 
sacerdotes para decir misa privadamente y administrar secretamente los sacramentos se holgaran que no hubiese en Irlanda mudanza de leyes, gobierno ni rey».

Se plantea así, por tanto, un marco idóneo para insertar una lista de nombres que se declaran servidores del rey español. Se trata de un documento que, según Enrique García Hernán, fue elaborado posiblemente por O'Sullivan en torno a 1611, a partir del análisis de la copia de este escrito que se conserva en la Real Academia de la Historia (N-11, ff. 163r-166v). ${ }^{30}$ En una búsqueda más amplia de testimonios, siguiendo el catálogo de la University College Cork, se pueden localizar tres traducciones al inglés. ${ }^{31}$ Esta multiplicación de testimonios — con copias que se circunscriben a las décadas de 1610 y 1620 - es sin duda un indicio claro del interés de este escrito para los exiliados y para la causa de Irlanda en ese momento. Pero en el archivo salmantino encontramos además otra copia del siglo XviII (n. 4.1., letra D), y otras dos diferentes del siglo XIX (n. 4.3. y 4.4, letra E). La existencia de copias tan tardías nos lleva a pensar que en los colegios de Castilla se mantuvo encendida la llama de la vinculación mítica y política de Irlanda con España durante muchos siglos, aun cuando el contexto político europeo era bien distinto.

El "proceso de ideologización» de la causa irlandesa se basó, al decir de Recio (2003: 234), en «tres principios fundamentales tales como su supuesta descendencia peninsular, su continuada catolicidad y sus servicios al Rey Católico». En esta línea, este escrito pudo formar parte de un conjunto de lecturas destinadas a reforzar la identidad fundacional de estos centros y a favorecer que los colegiales no se sintieran en tierra extraña, ya que existía una vinculación profunda y antigua entre castellanos e irlandeses [figura 2]. ${ }^{32}$

30. Puede consultarse la ficha de este documento en la Base de Datos de la Misión de Irlanda: <http://digital.csic.es/handle/10261/70221>, y siguientes.

31. Según el Corpus of Electronic Texts Edition del University College Cork [en línea: <www.ucc.ie/ celt/>]: [1] Dublín, Trinity College Library, Ms. E.iii.8, ff. 22, 49-52: «Briefe relation of Ireland and diversity of Irish in the same» (c. 1618), y «Priests of Ireland and Gentlemen gone abroad» (c.1625); [2] Dublín, Trinity College Library, Ms. E.iii.15, ff. 6, 11b: «The names of sundrie priests and friars within some dioceses and counties of Ireland, that you may see what number of priests were come over, and whether it were not time to look to their seducing of the subjects» (1624), $y$ «A note of the names of the Priests, Commissaries, Friars, and Jesuits, together with their relievers, and maintainors in the City of Kilkenny» (1613); [3] Dublín, University College, UCD-OFM, Ms. D.01, vol. 1, 1526: "Briefe relation of Ireland and diversity of Irish in the same» (c. 1618) [consulta 20/V/2017].

32. En los días de la Guerra de la Independencia, cuando las tropas de lord Wellington atravesaban la provincia de Salamanca, uno de sus capellanes de campaña, William Bradford (1780-1857), elaboró un reportaje de su viaje con dibujos de paisajes y tipos populares. En aquellos días, su mirada se fijó en los estudiantes irlandeses y realizó el retrato más antiguo que se conserva de uno de ellos, con la típica indumentaria colegial (figura 2). Un muchacho que pudo haber dedicado la mañana a leer (o a copiar) documentos semejantes a los que he comentado y que en su paseo vespertino se topó, paradójicamente, con aquel clérigo de la iglesia anglicana de cuya influencia huía al viajar hasta Salamanca. 


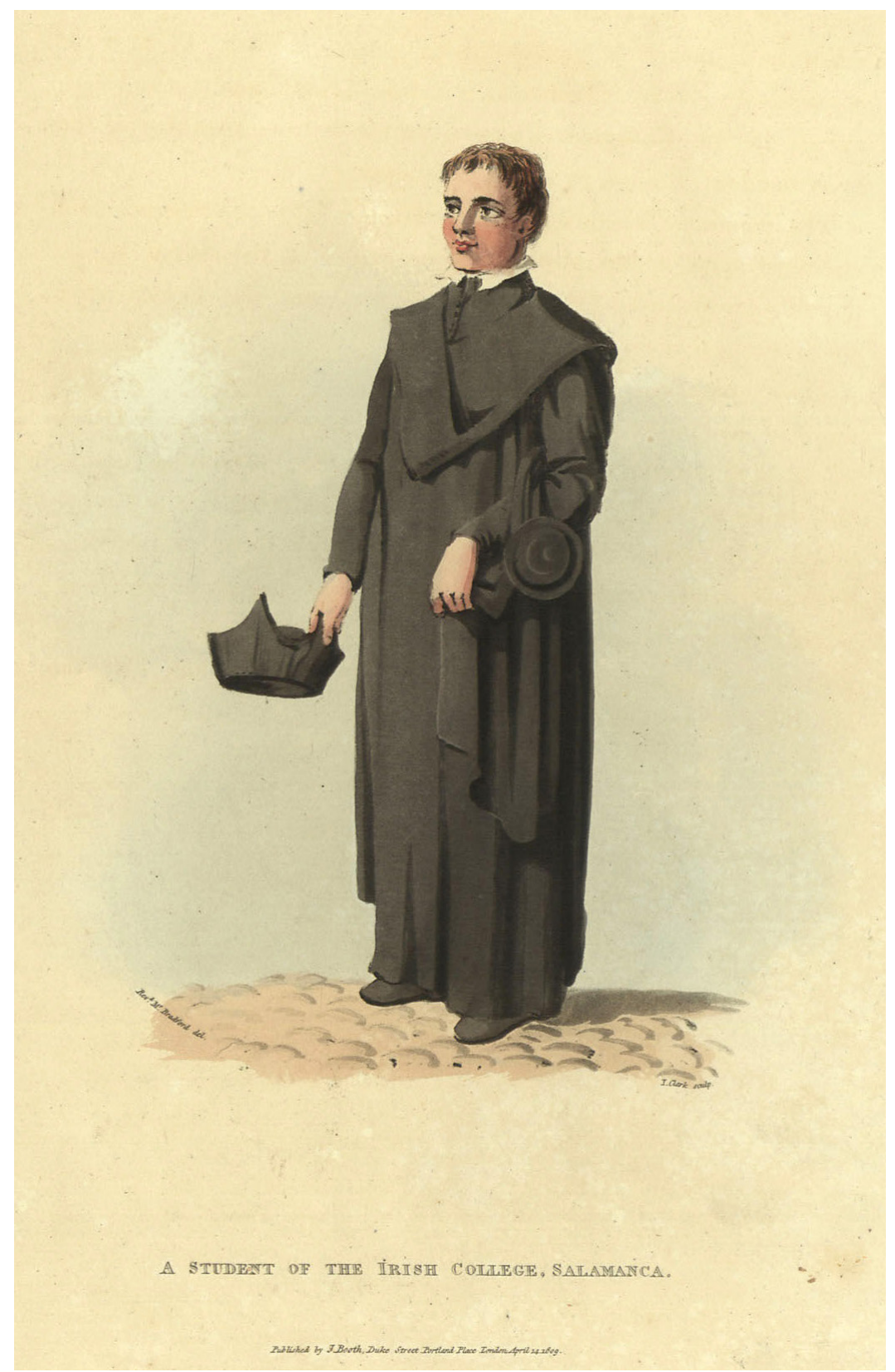

\section{Figura 2}

A student of the Irish College, Salamanca. William Bradford, Sketches of the Country, Character and Costume in Portugal and Spain, made during the campaign and on the route of the British Army in 1808 and 1809.

(London: John Booth, 1810, estampa n. 23) 


\section{El sol de los desterrados. Balance final}

Desde la Antigüedad, el exilio ha mostrado un tratamiento literario que se ha proyectado de múltiples formas en la cultura occidental. Algunos críticos, como Guillén (1995: 31ss), se han preocupado por estudiar los hitos más relevantes de este panorama, hasta identificar los modelos más habituales, desde una perspectiva más confesional a otra más evasiva. Pero el exilio de nuestros colegiales no encaja fácilmente en dichos parámetros. Según indica Pérez Tostado (2012: 62), que ha estudiado el exilio irlandés en esta época, "poco se sabe a ciencia cierta de las motivaciones psicológicas del exilio moderno». A pesar de su relevancia en los siglos XVI y XVII, «escasos son los testimonios sobre la manera en la que la inmensa mayoría de los desarraigados, incluidos los irlandeses, interpretaron el abandono de su tierra». ${ }^{33}$ Los testimonios que se han conservado sobre el exilio irlandés - continúa Pérez Tostado (2012: 62) — mantienen más bien una suerte de «ideología pública del exilio», ya que «la estructura social de la época moderna no entendía como tal el concepto de individuo». Dicha ideología se basa en la configuración de una «comunidad imaginada, basada en el origen geográfico y [la] religión común", y en la democratización de esta imagen ideal, que ya no es creada y percibida solamente por los más instruidos, sino que se proyecta de forma global en toda la comunidad de exiliados, como si se tratara de una gran movilización que incluye una solicitud de amparo permanente a la Corona espańola; cuestiones que están en sintonía con lo que he denominado discurso del exilio, terminología que considero más apropiada en la medida en que subraya la idea de una mentalidad creada, dirigida y proyectada sobre una determinada comunidad, de forma consciente e intencionada, con el objeto de transformar la realidad presente.

Por lo que tienen de relato geográfico, historiográfico y literario, las descripciones de Irlanda colaboraron eficazmente en la configuración de una identidad común frente a la Inglaterra anglicana. Son sin duda la encarnación más eficaz de esta "comunidad imaginada» que ayudó a los colegiales a entender su lugar en el mundo. Por otro lado, he propuesto como hipótesis que la composición y la lectura de estas obras pudo formar parte de una serie de prácticas intelectuales vinculadas al fortalecimiento de la identidad fundacional de estos colegios y a la adquisición de determinadas competencias lingüísticas y académicas. ${ }^{34}$

33. Este investigador plantea su propuesta en sentido europeo y en este trabajo me he referido prioritariamente a los irlandeses exiliados en Castilla. Para el caso italiano, debe verse el trabajo de Pellizzi (2011: 36-43).

34. Los colegios para ingleses ofrecen pruebas que avalan esta sugerencia. Las profesoras Cano y Sáez (2009) han editado un buen número de impresos y manuscritos vinculados al Colegio de san Albano (Valladolid) que dan cuenta de multitud de celebraciones y actividades literarias destinadas a la exaltación y justificación de su causa: epigramas, escritos laudatorios, jeroglíficos, emblemas, etc. 


\section{Bibliografía}

Álvarez Rodríguez, Román, El colegio de los irlandeses de Salamanca: un legado secular, Salamanca, Centro de Estudios Salmantinos, 2016.

Arellano, Ignacio (ed.), Loca ficta. Los espacios de la maravilla en la Edad Media y Siglo de Oro, Madrid, Iberoamericana, 2003.

Bravo Lozano, Cristina, «La Misión de Irlanda en la estrategia política de Felipe III", en Campo y campesinos en la España Moderna; culturas políticas en el mundo hispano, coord. por María José Pérez Álvarez y Alfredo Martín García, Madrid, Fundación Española de Historia Moderna, 2012, vol. 2, 1557-1566.

-, Tierras de misión: la política confesional de la monarquía de España en las Islas Británicas, 1660-1702, Tesis doctoral dirigida por Antonio Álvarez-Ossorio Alvariño y Enrique García Hernán, Universidad Autónoma de Madrid, 2014.

Burrieza, Javier, Una Isla de Inglaterra en Castilla, Valladolid, Real Colegio de san Albano, 2000.

—, "Escuelas de sacerdotes y mártires: Los Colegios del exilio católico», en Enrique García Hernán et alii (eds.), Irlanda y la Monarquia Hispánica: Kinsale 1601-2001. Guerra, politica, exilio y religión, Madrid, Universidad de Alcalá / CSIC, 2002, 39-74.

Cano, Berta y Ana Sáez-Hidalgo (eds.), The Fruits of Exile/Los frutos del exilio. Emblems and Pamphlets from the English College at Valladolid, Valladolid, The Royal English College, A.C.S.A. Series, vol. II, 2009.

Carrizo Rueda, Sofía M., «El purgatorio de San Patricio y la dramatización del relato de viajes: códigos, decorado verbal y texto literario», en Calderón 2000. Homenaje a Kurt Reichenberger en su 80 cumpleaños. Actas del Congreso Internacional, IV centenario del nacimiento de Calderón, Universidad de Navarra, Ignacio Arellano (dir.), vol. 2, 2002, 111-120.

Caro Baroja, Julio, Las formas complejas de la vida religiosa: religión, sociedady carácter en la España de los siglos XVI y XVII, Madrid, Sarpe, 1985.

Corish, Patrick. J. y Benignus Millet (eds.), The Irish martyrs, Dublin, Four Courts Press, 2005.

Cuntr Moner, Baltasar (ed.), Gil González Dávila, Historia de las Antigüedades de la ciudad de Salamanca, Salamanca, Diputación de Salamanca y Ediciones Universidad de Salamanca (ed. facsímile), 1994.

Dale, M. K., "Sir Robert Peckham», en The History of Parliament: the House of Commons 1509-1558, ed. S. T. Bindoff, Londres, Published for the History of Parliament Trust by Secker \& Warburg, 1982. Consultado on line el 15 de agosto de 2016, en <www.historyofparliamentonline.org/ volume/1509-1558/member/peckham-sir-robert-1516-69>.

Domínguez Lasierra, Juan, «La campana de Velilla en dos sonetos de Quevedo", Mar océana. Revista del humanismo español e iberoamericano, 8 (2001), 123-127. 
García Hernán, Enrique, Irlanda y el Rey Prudente, Madrid, Ediciones Laberinto, 2000.

—, «El colegio de San Patricio de los Irlandeses de Madrid (1621-1937)», Madrid: Revista de arte, geografía e historia, 8 (2006), 219-246.

—, "The Irish College at Valencia (1623-1680): Historical consequences», en Óscar Recio Morales (ed.), Redes de nación y espacios de poder: La comunidad irlandesa en España y la América española, 1600-1825. Power strategies Spain and Ireland 1600-1825, Valencia, Albatros, 2012, 93-102.

GeIsLER, Eberhard (ed.), La representación del espacio en la literatura española del Siglo de Oro, Barcelona, Anthropos, 2013.

Gibelli, Alberto, Memorie storiche ed artistiche dell' antichissima Chiesa abbaziale dei santi Andrea e Gregorio... sul Monte Celio, Siena, Tip. Arciv. S. Bernardino, 1888.

Guillén, Claudio, El sol de los desterrados: literatura y exilio, Barcelona, Sirmio (Quaderns Crema, Biblioteca General, n. 19), 1995.

Holloway, Anne y Ramona WraY, «O daughter... forget your people and your father's house': Early Modern Women Writers and the Spanish Imaginary", Bulletin of Spanish Studies, 7-8, 93 (2016), 1387-1413.

Hsia, R. Po-Chia, El mundo de la renovación católica, 1540-1770, Madrid, Akal, 2010.

Insúa, Mariela y Lygia Rodrigues Vianna Peres (eds.), Monstruos y prodigios en la literatura hispánica, Madrid: Iberoamericana / Frankfurt: Vervuert (Biblioteca Indiana, n. 20), 2009.

Kagan, Richard, "Clío y la corona: escribir historia en la España de los Austrias», en Richard Kagan y Geoffrey Parker (eds.), España, Europa y el Mundo Atlántico, Madrid, Marcial Pons, 2002, 113-147.

Kelly, J. E. y S. Royal, Early Modern English Catholicism Identity, Memory and Counter-Reformation, Leiden: Brill, 2016.

Lennon, Colm, Richard Stanihurst: The Dubliner, 1547-1618: A Biography with a Stanihurst Text on Ireland's Past, Dublin, Irish Academic Press, 1981.

Lozano Renieblas, Isabel, Cervantes y el mundo del «Persiles», Alcalá de Henares, Centro de Estudios Cervantinos, 1998.

MarCello, Elena, «El segundo "enredomado" de Álvaro Cubillo de Aragón y la campana de Velilla», Lectura y signo, 1 (2006), 61-72.

Moralejo, José Luis (ed.), Beda el Venerable, Historia eclesiástica del pueblo de los anglos, Madrid, Akal, 2013.

Morgan, Hiram, “Un pueblo unido...”: the politics of Philip O'Sullivan Beare», en Recio Morales, Óscar, Bernaldo J. García, Miguel Ángel de Bunes y Enrique García Hernán (eds.), Irlanda y la Monarquía Hispánica: Kinsale 1601-2001: guerra, politica, exilio y religión, Madrid: Universidad de Alcalá / CSIC, 2002, 265-282.

Murphy, M., Ingleses y Sevilla. El Colegio de san Gregorio, 1592-1767, Sevilla, Universidad de Sevilla, 2012. 
O'Connell, P., «The Early-Modern Irish College Network in Iberia, 15901800», en O'Connor, T. (ed.), The Irish in Europe, 1589-1815: 49-64, Dublín, Four Courts Press, 2001.

O'Connor, Thomas, Irish Voices from the Spanish Inquisition. Migrants, converts and brokers in early modern Iberia, London, Palgrave Macmillan, 2016.

O’SCEA, Ciaran, «Los exiliados de las islas británicas (1580-1680)», en Ruiz Ibáńez, J. J., e Igor Pérez Tostado (coords.), Los exiliados del rey de España, Madrid, Fondo de Cultura Económica de España, 2015, 107-130.

Pellizzi, Carlo Maria, "Ibernia fabulosa: per una storia delle immagini dell'Irlanda in Italia", Studi Irlandesi. A Journal of Irish Studies, 1.1 (2011), 29-119.

Pérez Tostado, Igor, "Ideología del exilio irlandés», en Los irlandeses y la Monarquía Hispánica (1529-1800). Vinculos en espacio y tiempo, Valladolid, Archivo General de Simancas y Ministerio de Educación, 2012, 61-70.

Profeti, Maria Grazia, Paradigma y desviación: Lope, Calderón y un tema barroco: "El purgatorio de San Patricio», Barcelona, Planeta, 1976.

Recio Morales, Óscar, «The Irish College of Alcalá de Henares (1630-1785) from an european perspective. A guideline to the Irish Colleges on the Continent: a Counter-Reformation cultural consequence», Indagación: revista de historia y arte, 2 (1996), 197-228.

- España y la pérdida del Ulster. Irlanda en la estrategia política de la Monarquía hispánica (1602-1649), Madrid, Ediciones Laberinto (Col. Hermes, n. 25), 2003.

Recio Morales, Óscar, B. J. García, Miguel Ángel de Bunes y Enrique García Hernán (eds.), Irlanda y la Monarquía Hispánica: Kinsale 1601-2001: guerra, politica, exilio y religión, Madrid: Universidad de Alcalá / CSIC, 2002.

Rey Castelao, Ofelia, «Exiliados irlandeses en Santiago de Compostela desde fines del XVI a mediados del XvII», en Irlanda y la Monarquía Hispánica: Kinsale 1601-2001: guerra, política, exilio y religión, Madrid: Universidad de Alcalá / CSIC, 2002, 89-112.

Riquer, Martín de, «Presentación al Simposio de Literatura Comparada 1977», 1616. Anuario de la Sociedad Española de Literatura General y Comparada, 1978, 57-58.

Salvador Miguel, Nicasio, Santiago López-Ríos y Esther Borrego (eds.), Fantasía y literatura en la Edad Media y los Siglos de Oro, Pamplona, Universidad de Navarra / Madrid, Iberoamericana, 2004.

Toвío, Luis, Gondomar y los católicos ingleses, La Coruña, Ediciós do Castro / Publicacions da Área de Ciencias Sociais e Políticas do Seminario de Estudos Galegos, 1987.

Vega Ramos, María José, Los libros de prodigios en el Renacimiento, Bellaterra, Universidad Autónoma de Barcelona / Seminario de Literatura Medieval y Humanística, 2002. 


\section{Apéndice documental}

Se ofrece en este apéndice la transcripción del documento n. 2. Como se trata de un escrito que puede interesar a investigadores de áreas de conocimiento muy diversas, he actualizado el texto siguiendo las normas de la ortografía actual. Los nombres propios y los topónimos se ofrecen según la redacción del original. Cuando es posible, se rescata entre corchetes dicho nombre en inglés actual. Entre corchetes se indica también el número del fotograma que se transcribe. Y entre paréntesis se incluye una numeración de los párrafos según figura en el original.

\section{"De algunas cosas raras que hay y ha habido en Irlanda» \\ (AUSA_IRL, carpeta 2, 264-275) \\ [264] † \\ De algunas cosas raras que hay y ha habido en Irlanda}

(1) Merece al primer lugar el no haber animal ponzoñoso en todo el reino, ni poderse sustentar en la tierra cosa que lo críe y haberse visto morir sobre ella, traída a donde los hay, sabandijas, culebras y otros tales, y aún la raspadura de sus árboles, como escribe Beda, es remedio contra el veneno y llagas enconadas, y añade que casi todas las cosas de esta isla valen contra el veneno. Este efecto se atribuye a la oración del glorioso san Patricio su apóstol, movido de compasión de verse perder tantas almas de los muchos animales venenosos que había antes de recibirse en ella la fe católica por su medio, y así en parte han sido causa que se perdiesen en ella tantos y tan varios linajes de gentes que en sus principios la fueron a cultivar. ${ }^{35}$

(2) Por intercesión del mismo santo descubrió Dios aquel célebre purgatorio que del santo ha tomado su nombre y apellido, el cual pide por sí un discurso particular y se pondrá adelante. ${ }^{36}$

(3) Otra maravilla es la isla que llaman de los vivientes, lugar muy a propósito para la penitencia, donde vivían antiguamente muchos santos de los cuales hay fama y tradición que nunca allá moría ninguno, antes llegando uno a edad ya decrépita, el Señor, por ministerio de ángeles o con oculta inspiración, les movía a salir de ella para morir e ir a recibir el galardón de sus merecimientos en el cielo; ahora está desierta pero frecuentada a sus tiempos de los peregrinos de allá con mucha devoción y penitencia. Junto a una de las iglesias que hay aquí, está una cruz de piedra algo gruesa y grande a la cual llegan con suma ve-

35. Remite al comienzo de la Historia ecclesiastica gentis Anglorum, compuesta por Beda el Venerable en el siglo viII (Moralejo 2013: 52). Es referencia tópica de buena parte de las descripciones de Irlanda.

36. Vuelve a referirse al purgatorio de san Patricio en $\$ 28$ y 39 . 
neración los peregrinos y extiéndense con ella, abrazándola, y después fíjanla [a] sus espaldas y vuelven las manos hacia atrás; ha se visto varias veces que nińos y muchachos la podrían abrazar de esa manera y hombres robustos y grandes no la pudiesen abrazar o juntar sus dos manos atrás, medio de que Nuestro Señor (si así se puede decir) se ha querido aprovechar para hacer algunas personas a caer en la cuenta de algunos pecados suyos para hacer digna penitencia de ellos. Y cierta persona de título me refirió que teniendo esto por cosa fabulosa, siendo mozo, de propósito [265] hurtó un libro y, pudiendo antes abrazarse con la dicha cruz, después no era posible hasta que hizo penitencia y confesándose y después púdola abrazar, el cual me afirmó también que es voz pública que con la demasiada ansia con que entran en el batel los peregrinos para la isla se ha visto varias veces dar vueltas la barca y con estar bien hondo el pasaje y caer ellos en el agua con todo eso no se ha visto ahogarse persona alguna. En llegar a dar vueltas a las iglesias y cruz andan en las rodillas desnudas tres veces en cada puerta, dentro y de fuera, y antes que entran reciben el santo sacramento de la penitencia. En varias partes donde dan estas vueltas métense en agua hasta la cintura, donde se lastiman mucho con las raíces de los árboles y los palillos y espinas que caen de ellos. En esta ínsula [ilegible] no entra mujer alguna, y una que tuvo atrevimiento de tentarlo se había ahogado, y en su lugar ha quedado en parte del lago una piedra que hasta hoy día se ve en medio del paraje, y así la romería de las mujeres [ilegible] esta gran hecho de la isla pero en contorno como de una buena legua. Todos los que hacen su romería aquí andan descalzos. ${ }^{37}$ Los tiempos en que la frecuentan son por la Semana Santa y san Miguel, bien recios e inclementes de ordinario.

(4) Hay otra isletallamada [hueco para copiar después el nombre] donde no solamente mujer pero ni pájaro ni animar del sexo femenino entra allí que no muera luego. Otros dicen que se mudan al sex[o v]iril.

(5) Lo que se dice de la cruz de esta isla se refiere casi de otra que está junta a la villa de Clonmelia [Clonmel] y se llama la fuente de san Patricio junta a la cual está otra que tiene tres vertientes o caños debajo de la cruz que hay: un año no corre gota por uno de ellos, otro año corre con mucha furia y el tercero muy poca, y así van mudando por sus veces los tres caños. En esta cruz y fuente se han visto maravillosos cuentos ${ }^{38}$ en nuestros días y así es frecuentado con devoción.

(6) En el lugar de Tiddimoling, Domus Molingi [Timolin], dentro de 4 millas de Rosia, hay otra semejante fuente que tiene dos caños y corre un año por uno y por otro; otro año el agua [es] obradora de milagros.

(7) Hay otra isla, rodeada del océano, que llaman de san Miguel, que los naturales dicen Seregmihis [Skellig Michael, gaélico Sceilig Mhichíl, 'Roca de Miguel'], [266] y es maravillosa cosa que las aves que vuelan sobre ella, perdien-

37. Utiliza siempre romeira en lugar de romería.

38. cuentos, con el sentido de "relación o noticia de alguna cosa sucedida» (Autoridades, sv.). 
do su vuelo y ligereza natural como hierro o piedra, caen en el suelo sin poder jamás tomar vuelo. Dícese que antiguamente, a intercesión de un santo que hacía áspera penitencia y vida santa en esta isla, Nuestro Señor enviaba como codornices o maná a su pueblo, así a los que iban desproveídos a tratar las cosas de sus almas con este su siervo, la cual bendición ha guardado hasta hoy día. Cuando hace buen tiempo, los vecinos entran aquí por su devoción y cogen con grande facilidad las que quieren con las manos. Y no hay mucho que un inglés hereje, burlándose de lo que le decían de esta isla, quiso irla a ver y cazar como los demás, y apenas había puesto pie en aquella tierra santa, cuando luego se le atemblaba todo el cuerpo y le dio tan terrible flujo de vientre que por poco quedara allí yerto si no le llevasen luego a su batel, cayendo en la cuenta y sintiendo en sí el verdadero castigo de su incredulidad.

(8) Hay otro territorio en el distrito de Kilkenia [Kilkenny] que se dice Hidnach donde nunca se halla conejo, ni se ha visto parar los gansos bravos, con haber de los unos y otros mucha cantidad en toda la tierra vecina al derredor. $\mathrm{Si}$ meten ahí conejos (donde parece hay buena comodidad para ellos), luego huyen de ahí como del fuego y si cae ganso nunca más puede coger vuelo.

(9) No es menos de maravillar la calidad del agua de san Molazo [st. Mullins], la cual, bebida por un perjuro, reviéntasela por su vientre u otra parte, y cierta persona grave ha visto un hombre herido con cierta llaga no curable en el vientre por haber bebido y no creído esto, y luego se le comenzó a salir por el vientre agua y se quedó con una como fuerte toda la vida. En esta tierra y su comarca tiénese por muy grave cierto juramento jurar por las aguas de san Molazo [st. Mullins].

(10) Había parecida en nuestra Irlanda un árbol colgado de rosarios de la Virgen Nuestra Señora e otra de cuentas.

(11) Y hoy día hay otra que da cuatro veces al año fruta muy sabrosa y me lo afirmó quien de ellas comió. Llámase el lugar en donde nace Truckmhequenan, en la Provincia de Ultonia [Ulster]. [267]

(12) Un templo y cementerio fundado y sustentado milagrosamente sobre un pantano despide y echa de sí los cuerpos muertos que se entierran en él.

(13) En el lago que llaman Lochllen, en el condado de Desmonia [Desmond], parece una luz de extraordinario resplandor todas las noches como de una hacha y se extiende a grande trecho y de tal manera alumbra que quien estuviera en un batel fácilmente podría descubrir el suelo con ser muy hondo. Sospéchase que hay allí un carbunco, y con haber muchos que los buscasen nunca han podido atinar con él.

(14) En la provincia de Kierry [Kerry] hay un árbol cuyos frutos se convierten en ánades no mucho después que caen en el agua. Jurolo una persona fidedigna como testigo de vista.

(15) En el territorio que llaman de Tiramhly en Conacia [Connacht], si le echan en el lago una pértiga o palo, lo que tocare en el suelo se vuelve en piedra, lo que está dentro del agua en hierro, y lo restante se queda palo como antes 
pero para esto se requiere algún tiempo, como lo refiere Hector Boetio en su prefacio. ${ }^{39}$

(16) En la provincia de Conacia [Connacht] y territorio de Brena y lugar de Kildrofardon, cualquiera cuerpo muerto enterrado en la iglesia de Nuestra Señora que ahí está, en 24 horas se halla convertido en polvo, sólo quedan los huesos mondos que parecen alabastro, $y$ añaden que nunca se ha visto ahí gusano ni otra sabandija que de ordinario roen y comen los cuerpos de los difuntos.

(17) En el lago de Roseoman y contorno de Brieny ruerque, de la provincia de Conacia [Connacht], hay una capilla y en ella una fuerte de agua clara donde hay un pez a manera de trucha grande con espejos, pelos y no muy largos, desde la cabeza hasta la cola por la espina abajo, el cual a cualquiera hora del día o noche que uno le extiende un pedazo de pan y lo recibe él de su mano, se tiene el otro por persona sana y si no lo toma presupone o muestra que tiene ese tal alguna enfermedad, de la cual se ha sucedido morir diferentes personas. Los idiotas, como siempre suelen, de particulares acaecimientos sacan generales conclusiones, dicen que el no recibir este pez o trucha el pan es argumento de su corta vida y pienso que el temor de esto la hacen perder más que otra cosa. [268] Ha que está aquí mientras se acuerdan los moradores de mayor edad que de ella tienen tradición de sus pasados.

(18) En esta misma laguna está una losa algo levantada donde pueden estar en pie cuatro hombres y en la mitad de ella una cruz en cuyo remate está un agujero. El que no sabe nadar poniendo el dedo pulgar del pie en el dicho agujero y dando tres vueltas al derredor en nombre de la Santísima Trinidad y encomendándose a ella, a la Virgen Nuestra Señora y a san Miguel, besando y adornando la dicha cruz extendiéndose en el agua, acierta a nadar como si lo hubiese platicado mucho tiempo. Dieron fe y testimonio de esto personas que lo experimentaron.

(19) A la otra parte de la Iglesia que llaman Kilocea, en la tierra del señor Oszalano Bierras, ${ }^{40}$ están tres terrones de tierra y juncos, y no obstante que en este puesto anda la mar con sus crecimientos y menguantes y muchas veces con grandes tempestades viénense poco a poco atravesando aquel brazo de la mar todos los domingos del año de suerte que ya llega a la hora de la misa y paran sin menearse junto a la Iglesia hasta las doce y vuelve de la misma manera como vinieron a su lugar, y es tan infalible esto que no hay morador ni vecino que sepa hubiese faltado un solo día y tan antiguo que no hay quien se acuerda cuando comenzasen, solamente oyeron de sus antepasados que solían venir todos tres juntos, pero que después que cierta persona tiró una darda dejándola en una de ellos, desde entonces acá viene un poco tras los otros dos, son tantos los testigos de vista de este caso que sería por demás otras averiguaciones para su comprobación.

39. Debe referirse a la Historia Gentis Scotorum compuesta por Hector Boece (1465-1536).

40. Nombre de difícil comprensión, escrito entre líneas sobre otro nombre tachado. 
(20) En Tirchonel y lugar llamado Toarmuingortan (donde nació san Columbano) hay un cementerio de la Iglesia cuya tierra, llevada a mujeres en tiempo de parto, y en virtud de ella, se han visto varias y casi las más veces muchas en gran peligro bien parir.

(21) En este mismo lugar hay una piedra por la cual si se jura con mentira despide por la mano del perjuro un humor a modo de sudor que no puede encubrir el perjuro.

(22) En una isleta, no lejos de la ciudad de Limirique [Limerick] llamada [269] Inisqueltar, vivió un santo llamado Camino, ${ }^{41}$ el cual alcanzó del Señor que los que allá viniesen en romería haciendo lo siguiente serían librados de la peste que correría. Y es de saber el modo de esta peregrinación: éntrase en ella en cierta parte determinada, por donde entraron los santos que en ella vivían (por ventura para venir a parar en otros tales que ellos) dando la vuelta siete veces a la isla descalzos. El camino está sembrado de chinas a[s] peras a cada Iglesia de las siete que hay otras tantas y de la misma manera a cada cementerio y monumento que cada Iglesia tiene dos noches que de dormir sobre calvario y la tercera sobre monumento del santo. En todo este tiempo ayunan con gran rigor, nunca sueltan el rosario de las manos, tienen varitas con que dan en sus piernas, brazos y espaldas con las cuales se lastiman mucho (modo muy antiguo de disciplinarse los penitentes en nuestra patria) y déjanse sobre un altar o escaño de alguna capilla; y tienen estas puestas en diferentes partes para las mujeres y hombres, por evitar algún peligro que pueda acontecer; confiésanse los que pueden y así salen regocijados y contentos. Este modo está puesto por el dicho santo Camino el cual alcanzó de los sumos pontífices grandes indulgencias y gracias para los que esta romería hacen a la manera dicha y del Señor lo que está dicho y referido.

En el territorio de Tiramsilis, junto a la Iglesia Aderquia, está una fuente perpetuamente, cinco pies distante del lago que se dice Lochcon, y nunca más ni menos, ora se mengüe en el estío, ora recrezca en el invierno o con avenidas de agua y mucha lluvia.

(23) En el distrito del señor Maguir hay una iglesia y en ella una campana de la cual está colgado una soga o cordel que se pone a la garganta del que traen por sospechoso para jurar: si miente de suyo y del tal manera le va apretando que muchas veces se ahoga sin remedio el perjuro; si dice verdad, libre se queda.

(24) En el condado del señor Conochur Gleguy y lugar llamado Inismares se conserva un fuego que nunca se apaga sin que le echen materia alguna. En el tiempo de peste los que pasan por el río que está junto [270] a una iglesia llamada Invernal y hacen en ella oración devota no son tocados de la pestilencia. Está en el dominio del señor O’Donel [O’Donnell, señor de Tyrconnell]. Hase com-

41. La referencia a este impreciso san Camino parece errónea, sobre todo para un lugar donde quizá es más propio citar a san Senan. 
probado esto varias veces y ahora, en nuestros días, créese que el Señor otorgó este privilegio por intercesión de algún santo que por ahí vivía antiguamente.

(25) En la villa de Squein, donde hay doce iglesias, cualquiera persona de la familia de los Burgos (que es muy noble en el reino) que va o mira en él, o se consume como tísico o presto muere. En nuestros días, unos de ellos, teniendo esta por fábula, fue a probarlo y sucediole lo dicho. Dicen que uno de los santos que allá vivían y tenía revelación profética que de esa familia vendría mucho mal al reino, alcanzó del Señor por castigo y escarmiento de los demás aquella pena con la cual parece se pone freno a la curiosidad y memoria de los delitos de sus antepasados, porque no les castigue a ellos, también como a aquellos con otra que tal supe después de escrito esto, que el conde Rojas, uno de los hijos y más nobles de esta familia, que fue conde de Kente (Kent) en la Inglaterra, teniendo noticia de esta profecía y estando en el mismo puesto, preguntó cómo se decía, y sabiéndolo se apareció luego para su muerte, y de hecho fundó el monasterio de Rahasel, 3 millas de Casel [Cashel], y antes de acabársele el año murió.

(26) Junto a Quilmechiloq, en el pueblo llamado Brary, algunos siglos hay que parece un frasco de oro o dorado sobre el río por un poco trecho, y el que lo ve da parte de él al señor del lugar legítimo, que siempre es de la familia de los Lesios, y él se dispone para ir a dar cuenta a Dios, y dentro de poco tiempo se ve que muere. Efecto confirmado a esta casa puede ser por algún bien particular que hubiere hecho algún señor de aquella familia que yo no pude averiguar hasta ahora y que quiere el Señor amonestar algunos de su muerte algún tiempo antes es cosa que puede y sabe hacer, como lo acontecía por mucho años en el convento de los padres predicadores [271] del santo Domingo, en Zamora, con la voz y sonido de cierta campanilla que de suyo tañía cuando había de morir alguno, con la cual todos se aparejaban y uno sólo moría.

(27) En Kilmachinan, del distrito de Tirchonel [Tyrconnell], hay una fuerte de agua clara y cuando se ha de morir el señor de aquella tierra, que es O’Donel [O’Donnell], se ve que el agua se vuelve en sangre o al menos en color de sangre. Otro presagio tiene la casa y familia de Macartymor [MacCarthy More] por un ruido extraño que hace el puerco marino o foca que se acerca a la pared de un castillo que tiene este señor en la orilla del mar. ${ }^{42}$

(28) De nuestro insigne patriarca y apóstol san Patricio de quien entre otras maravillas se cuenta que siempre traía consigo un báculo que los nuestros llaman «bachal Jesu» con el cual echaban del reino los animales ponzoñosos. Abrió la cueva de su purgatorio y hacía otros efectos como Moisén con su vara. Si uno se había fatigado y cansado luego se sentía aliviado y muy alentado para andar

42. Bajo esta línea, el autor tacha el siguiente texto: «Dejándose otras muchas cosas aparte por no las haber de personas fidedignas o por no saber el lugar y el modo con otras circunstancias iremos acercándonos a las cosas». Y en el ladillo izquierdo, cancela esta otra: "Hase de poner esto en otra parte, con todo lo que toca al del báculo: plato, altar, ara, casulla, coquilla, campana, piel, sombra, pierna, sepulcro». 
mucho más. Dícese que en las astillas de este báculo que llevaban muchos devotos por reliquias se hallaba escrito en ellas el dulcísimo nombre de Jesús.

(29) Un plato de que se servía el santo y hoy día tiene un noble caballero (que no se nombra por justos respetos) está muy agujereado en el cual presentan la venida a un enfermo y si la retiene señal es que ha de cobrar salud y si no que presto ha de morir, hase visto varios efectos de esto. ${ }^{43}$

(30) El barón de Insiquin tiene un cierto lugar determinado donde, si entra, muere dentro de un ańo, y el señor O'Conordo un otro tal.

(31) El conde de Clamicard [Clanrickard], un monstuo marmo que llama Oleseste que parece antes de su muerte en el lago llamado Lochriach.

(32) El conde de Tomonia [Thomond], una voz lamentable de algún espíritu o fiera que llaman Beansi, ${ }^{44}$ [272] Tiene el reino de Irlanda por una de las principales sus insignias y armas su harpa ${ }^{45}$ coronada, que en hechura, artificio, ingenio y aún música y harmonía, a juicio de los más diestros músicos de los reinos circunvecinos excede a todas las otras, y se iguala a los otros muy señalados instrumentos que se usan. Suelen los diestros en ella tocar de tal manera en las florestas y campos que a manadas se llegan a su consonancia los venados y su poco a poco se extienden delante del que tañe y con el música adormecen; en el entretanto los cazadores arman sus redes y lazos y con las voces que dan despiertan los venados despavoridos y dándose a huir vienen con grande mansedumbre a poner su cabeza sobre los pechos del que tañe y al fin a adormecerse. Esto me [ha] referido persona noble y muy fidedigna que, juntamente fue testigo de vista. Tiene cierto dominio sobre los corazones de los irlandeses las músicas y tonadas propias del reino, que si se tañen bien por instrumentos se están palpitando, y se [ha] advertido que no hace este efecto en otros circunstantes. Y sabiendo los espíritus buenos o malos esta inclinación entretiénenles con tales muchas veces en lugares solitarios.

(33) Aquí estuvo el pájaro o antes ángel que entretuvo el santo abad del monasterio Clunyensi, no lejos de Ballalom trescientos años dándole música celestial.

(34) Escribe Geraldo Cambrinse ${ }^{46}$ dist. 2 de su Topographia, que en la villa de Quildar [Kildare] la santa virgen Brígida tuvo un género de fuego que nunca se mataba y que se traía al derredor en círculo al cual ningún hombre se atrevía a entrar y si alguno se atrevía luego sentía el castigo del cielo. ${ }^{47}$

43. Este punto continúa con el siguiente texto, que aparece cancelado en el original: "pronósticos de la muerte en varias familias nobles del rey no es cosa maravillosa y ordenada».

44. Utiliza feria por fiera.

45. Se mantiene la grafía harpa, con ortografía culta, que repite en los ladillos. Y después se mantiene también harmonía.

46. Esto es, Giraldo Cambrese, que escribió una Topographia Hibernica en el siglo XII, publicada en 1584 .

47. Brígida de Kildare (451-525), patrona de Irlanda, fue bautizada por san Patricio. 
(35) Hoy día, en este pueblo, está la casa y aposento y ventana donde la santa virgen solía estarse en oración mirando al cielo y si ponen en esta ventana una luz o vela encendida, por más viento y tempestad que haga no la mata ni hace mella en ella que como si no lo hubiese. [273]

(36) En muchas partes de la isla nace de los navíos como una espuma cuajada del lodo o alga marina y poco a poco se va endureciendo hasta a venir a ser conchitas dentro de las cuales se forman unos animalejos que la comienzan a abrir y crecidas les nacen plumas, andan en el agua como ánades cuando se les endurecen pueden volar como los demás aves, cómense y son sabrosas. Los naturales les llaman bernácula. Críanse de esta manera: millares de ellos juntos y porque no se engendran como las demás aves, ni nace, ni se crían porque nunca ponen huevos y siempre están alrededor de la mar, algunos antiguamente las comían como peces en días de ayuno. Hay tantos testigos de esto cuantos viven donde nacen.

(37) En el paraje de Kilkenia [Kilkenny] para Drihidberaned está una piedra que se llaman Kolpeapadric: es a decir la pisada de san Patricio y así parece ella pisada de un hombre, pero bien honda y hueca, y afirman que los que por ahí pasan cansados metiendo dentro su pie con devoción y fiados de él que se les quita el cansancio. (38) La misma eficacia dicen que tiene otra piedra que también tiene el nombre de san Patricio tomando en la mano.

(39) A la otra parte de Kilkenia [Kilkenny], como a 3 o 4 millas de ella y no lejos de Donmor [Dunmore], hay una profundísima cueva debajo de tierra donde hay varios apartamientos y concavidades do se recogen muchedumbre de aves y particularmente de palomas (de quienes se aprovechan los comarcanos en grande abundancia) y por su horrenda profundidad y variedad de cosas que se ven en ella acuden muchos a verla. Nadie se atrevió a tentar lo profundo aunque se dicen entraron en ella camino de 4 y 6 y 7 días con golpe y cantidad de hachas y velas hasta acabárselas; críase allí dentro mármol blanco que se cuaja de la destilación del agua por la tierra ancha y cuando viene a cuajarse mucho cae abajo y así dicen el camino está sembrado de ella. Unos piensan que es alguna de las cuevas soterradas donde hay algunas almas penándose, otros que sería algún mineral, otros que ha sido camino que se abrió con artificio de azogue o terremoto, pero yo no he podido hasta ahora averiguar qué pueda ser [274] ni más efectos de ella de lo que aquí refiero.

(40) Escribe Sabélico que hay en nuestro reino un lago donde el fresno se vuelve en avellano y, al revés, el avellano en fresco. ${ }^{48}$

(41) En nuestros días dicen que un monte que estaba a la orilla de un río sobre el que había entre ciertos señores diferencia, se puso entera y totalmente a otra parte.

48. Se refiere al historiador italiano Marco Antonio Sabellico (1436-1506), posiblemente a sus Annotationes in Plinium (1487). 
(42) Aunque ha algunos años que se ha visto en varias partes lluvia de cera en este año de 1607 cayó un buen golpe de ella el día de santa Magdalena y Santiago en la ciudad de Waterfor [Waterford], de la cual nos enviaron la muestra y parece como otra cualquiera. ${ }^{49}$

(43) El río Selis, que sale del famoso lago Ern [Erne], solía llevar gran copia de pesca y cierto día que echó san Patricio su maldición por haber maltratado él a su gente un rey llamado Caribre, hasta hoy día no se ha visto en él pesca alguna, con ser la cantidad de la pesca del lago inmensa y con estar de ahí abajo 4 leguas el mismo río también lleno de salmones, truchas y otra pesca. Joce, urt, S. Pat. C $53 .^{50}$

(44) En el lago llamado Lochnich, no lejos de Dunquenan, en la provincia de Ultonia [Ulster] y distrito del príncipe Oneil, hame referido una persona que lo vio y probó, cómo un palo que se sacó de ahí, dándole con un cuchillo, cortó lo que era palo, y que no podría cortar lo que era piedra, y mucho menos lo que era hierro, y añade que todos los árboles que nacen en este lago son de la misma condición..$^{51}$

(45) Cierto bosque de donde san Patricio quiso aprovecharse de una poca de madera para rehacer su carro quebrado varias veces se le rompía, y sabido después que era consagrado a los falsos dioses una vez que le echó su maldición nunca más madera ni árbol de él podía aprovechar para otra cosa que para el fuego. ${ }^{52}$ Tor C. $127 .{ }^{53}$

(46) En el lugar llamado Nadesi, por la burla que los moradores habían hecho antiguamente a san Patricio, haciéndole de propósito aguardarles ahí hasta muy a la tarde, desde entonces acá ni ellos ni ninguno de sus descendientes pudo acabar la obra comenzada para las vísperas por poca que fuese. ${ }^{54} \mathrm{Idem}$. c. $128 .[275]$

(47) Unos hombre ruines hicieron burla y daño a san Patricio impidiéndole ${ }^{55}$ el edificio de una iglesia no lejos de Visnedi, a los cuales como iba a echar maldición fuele a la mano san Segundino rogándole que cayese no sobre los hombres sino sobre las piedras de allí, y así fue y mostró el efecto la verdad porque hasta hoy día nunca más pudieron servir para edificio alguno, si acaso echaban en él algunas piedras de estas caían la tal obra en breve, y si las echan

49. Santa Magdalena se celebra el 22 de julio y Santiago el 25 de julio. Desde ese lugar se envió (supuestamente a España) una muestra de esa lluvia. Por este motivo, el texto se escribió a finales de 1607.

50. Referencia bibliográfica que no se ha podido localizar.

51. Párrafo cancelado con un aspa.

52. Párrafo cancelado con un aspa.

53. Referencia bibliográfica que no se ha podido localizar, al igual que la del párrafo siguiente (\$46).

54. Párrafo cancelado con un aspa.

55. impidiéndole] impediéndole. 
en la lumbre cuando se rompen no hacen ruido, y cuando acaece a dar consigo algún edificio en tierra dicen ahí estar la piedra de Bilmeis maldecida por san Patricio. Esta frase es también como en tierra de Kilkenia [Kilkenny] y dicen que las piedras del río Drinin se han quedado con esta maldición hoy día, y se ha visto que personas andando en ellas con seguridad dan vueltas y ahóganse de repente.

(48) Hay un cementerio en el territorio de [hueco en blanco para poner el nombre] donde nunca entra un perro, y si acaso se halla ahí muérese de repente como se ha visto, de lo cual [...] maldición que echan a quien [...] allá [...] y nunca más $[. .$.$] como a los perros de Nacave.$ 